\title{
The effect of phytostabilization on Zn speciation in a dredged contaminated sediment using scanning electron microscopy, X-ray fluorescence, EXAFS spectroscopy and principal components analysis
}

Frédéric Panfili ${ }^{1,2,5}$, Alain Manceau ${ }^{1 *}$, Géraldine Sarret ${ }^{1}$, Lorenzo Spadini ${ }^{1}$, Tatiana Kirpichtchikova ${ }^{1}$, Valérie Bert ${ }^{2}$, Agnès Laboudigue ${ }^{2}$, Matthew A. Marcus ${ }^{3}$, Noureddine Ahamdach $^{4}$, Marie-Françoise Libert ${ }^{5}$

\footnotetext{
${ }^{1}$ Environmental Geochemistry Group, LGIT, University J. Fourier and CNRS, BP 53, 38041 Grenoble cedex 9, France

${ }^{2}$ CNRSSP, BP 537, 59505 Douai cedex, France

${ }^{3}$ Advanced Light Source, Lawrence Berkeley National Laboratory, University of California, Berkeley, CA 94720, USA

${ }^{4}$ LESTS, IRSN, BP 6, 92265 Fontenay-aux-Roses cedex, France

${ }^{5}$ LMTE, CEA-CADARACHE, 13108 Saint Paul lez-Durance, France
}

*Corresponding author: Alain.Manceau @ujf-grenoble.fr

Keywords: SXRF, EXAFS, phytostabilization, speciation, Zn, sediment, Running Title: Effect of phytostabilzation on $\mathrm{Zn}$ speciation in dredged sediment 


\begin{abstract}
The maintenance of waterways generates large amounts of dredged sediments, which are deposited on adjacent land surfaces. These sediments are often rich in metal contaminants and present a risk to the local environment. Understanding how the metals are immobilized at the molecular level is critical for formulating effective metal containment strategies, such as phytoremediation. In the present work, the mineralogical transformations of $\mathrm{Zn}$-containing phases induced by two graminaceous plants (Agrostis tenuis and Festuca rubra) in a contaminated sediment $\left([\mathrm{Zn}]=4700 \mathrm{mg} \mathrm{kg}^{-1},\left[\mathrm{P}_{2} \mathrm{O}_{5}\right]=7000 \mathrm{mg} \mathrm{kg}^{-1}, \mathrm{pH}=7.8\right)$, untreated or amended with hydroxylapatite (AP) or Thomas basic slag (TS), were investigated after two years of pot experiment by scanning electron microscopy coupled with energy-dispersive spectrometry (SEM-EDS), synchrotron-based X-ray micro-fluorescence ( $\mu$-SXRF), and powder and laterally-resolved extended X-ray absorption fine structure ( $\mu$-EXAFS) spectroscopy. The number and nature of $\mathrm{Zn}$ species were evaluated by principal component (PCA) and least-squares fitting (LSF) analysis of the entire set of $\mu$-EXAFS spectra, which included up to 32 individual spectra from regions of interest varying in chemical composition. Seven $\mathrm{Zn}$ species were identified at the micrometer-scale : sphalerite, gahnite, franklinite, Zncontaining ferrihydrite and phosphate, (Zn-Al)-hydrotalcite, and Zn-substituted, kerolite-like, trioctahedral phyllosilicate. Bulk fractions of each species were quantified by LSF of the powder EXAFS spectra to linear combinations of the identified Zn species spectra.
\end{abstract}

In the untreated and unvegetated sediment, $\mathrm{Zn}$ was distributed as $\sim 50 \%$ (mole ratio of total Zn) sphalerite, $\sim 40 \%$ Zn-ferrihydrite, and 10-20\% (Zn-Al)-hydrotalcite plus Znphyllosilicate. In unvegetated but amended sediments (AP and TS), ZnS and Zn-ferrihydrite each decreased by 10 to $20 \%$ and were replaced by Zn-phosphate ( $30-40 \%)$. In the presence of plants, $\mathrm{ZnS}$ was almost completely dissolved and the released $\mathrm{Zn}$ bound to phosphate $(\sim 40$ $60 \%)$ and to Zn phyllosilicate plus (Zn,Al)-hydrotalcite ( 20-40\%). Neither the plant species 
nor the co-addition of mineral amendment affected the $\mathrm{Zn}$ speciation in the vegetated sediment. The sediment pore waters were supersaturated with respect to $\mathrm{Zn}$-containing trioctahedral phyllosilicate, near-saturation with respect to $\mathrm{Zn}$-phosphate, and strongly undersaturated with respect to $(\mathrm{Zn}, \mathrm{Al})$-hydrotalcite. Therefore, the formation of $(\mathrm{Zn}, \mathrm{Al})$-hydrotalcite in slightly alkaline conditions ought to result from heterogenous precipitation on mineral surface. 


\section{INTRODUCTION}

The regular dredging of sediment from waterways is necessary to enable navigation and prevent flooding. In France, due to the absence of regulations, dredged sediments are usually deposited on nearby soils, and as a result of anthropogenic activities including mining, industry and agriculture, often contain high amounts of metals. When the sediments are buried the mobility and toxicity of metals are low because the metals are generally present as sparingly soluble sulfides (O'Day et al., 1998; Davis and Atkins, 2001; Isaure et al., 2002; Osan et al., 2002; Maes et al., 2003; Motelica Heino et al., 2003; Neuhausler et al., 2003). In contrast, exposure of the sediments to the atmosphere can result in the oxidation of sulfides and release of metal contaminants to aquifers and streams (Kersten and Förstner, 1986; Zhuang et al., 1994; Cauwenberg and Maes, 1997; Carroll et al., 1998; Cauwenberg et al., 1998; O'Day et al., 2000; Fajtl et al., 2002; Isaure et al., 2002). The local environment may also be contaminated by aerial dispersion of metal-rich particles.

Owing to the huge volume of dredged sediments (e.g., $200,000 \mathrm{~m}^{3}$ year $^{-1}$ in the north of France), decontamination by chemical and physical treatments is impractical. One attractive alternative to the management of dredged sediments is phytostabilization, which is commonly used as a method to reinstall vegetation cover on highly contaminated and phytotoxic areas (Cunningham et al., 1995; Mench et al., 2003a). This approach to reducing the mobility of metals consists of adding chemically-reactive mineral amendments to establish vegetation with metal-tolerant plant species (Berti and Cunningham, 2000). A large number of amendments have been tested, including lime (Li and Chaney, 1998; Hamon et al., 2002), Fe and Mn oxyhydroxides (Mench et al., 1994a; Mench et al., 1994b; Mench et al., 2000; Mench et al., 2003a), hydroxylapatite (Chlopecka and Adriano, 1996; Cotter-Howells and Caporn, 1996; Laperche et al., 1996; Greman et al., 2001; Seaman et al., 2001), alumino-silicates including zeolite (Chlopecka and Adriano, 1996; Knox et al., 2001) and beringite (Vangronsveld et al., 
1995a; Vangronsveld et al., 1995b; Vangronsveld, 1998), and steel residues including Thomas basic slag (Mench et al., 1994a; Mench et al., 1994b) and steel shot (Sappin-Didier, 1995; Mench et al., 2003a). Beringite, steel shot, and hydroxylapatite are particularly efficient and lasting amendments, especially when used in combination (Boisson-Gruppen, 1999; Mench et al., 2003b).

Plant species tested in phytostabilization experiments are often grass species, such as Agrostis tenuis, Festuca rubra and Deschampsia caespitosa (Vangronsveld et al., 1995b; Li and Chaney, 1998; Bert et al., 2003). The grass species have low root-to-shoot transfer coefficients and, thus, limit the propagation of metals into the food chain. Plants can modify metal speciation in several ways. Absorption of water by roots together with the establishment of a dense root net can modify the redox properties of compacted substrates (Marseille et al., 2000). Plants, fungi (Sarret et al., 2003) and microorganisms that are tightly associated with roots, modify locally the chemical properties of the soil by exuding organic molecules and exchanging ions (e.g., $\mathrm{H}^{+}, \mathrm{OH}^{-}, \mathrm{HCO}_{3}{ }^{-} \ldots$ ) with the soil solution (Marschner, 1995; Hinsinger, 1998). As a result, metals can be taken up by plants or precipitated at the root surface (CotterHowells et al., 1999).

Although the reduction of metal mobility by adding mineral amendments and sowing metal-tolerant plants has been demonstrated in several case studies (Vangronsveld, 1998; Mench et al., 2003b), little is known about the mechanism of metal immobilization at the molecular-scale. This knowledge is essential to optimize the retention of metals, both quantitatively and definitely by enhancing their sequestration into stable forms. Extended Xray absorption fine structure (EXAFS) spectroscopy is a tool of choice for studying the speciation of metals in chemically-complex and structurally-heterogeneous natural matrices as a result of its sensitivity to the local structure of metals, its elemental specificity, and its low detection limit (about 100 ppm for $\mathrm{Zn}$ in a soil matrix) (Manceau et al., 2002a). If the element of interest is present in several forms, their identification can be challenging because the 
EXAFS signal is the weighted sum of the individual spectra from the component species. To reduce the number of components or modify their proportions, physical and chemical treatments can be used to remove or concentrate certain species (Manceau et al., 2000; Isaure et al., 2002; Scheinost et al., 2002; Juillot et al., 2003). Alternatively, the size of the X-ray probe can be adapted to a particular scale dependent on the heterogeneity of the sample. For soils and sediments, the micrometer scale of resolution is appropriate because fine particles of similar composition and structure formed by biotic and abiotic natural processes tend to aggregate (Manceau et al., 2000; Isaure et al., 2002, 2005; Manceau et al., 2002b; Roberts et al., 2002; Kirpichtchikova et al., 2003; Manceau et al., 2004; Sarret et al., 2004). This second approach is preferable because it is less invasive than chemical extraction (Ostergren et al., 1999; Calmano et al., 2001). Regardless of the approach used, the set of EXAFS spectra obtained either on soil fractions after physical or chemical treatments, or on minimally perturbed soil by $\mu$-EXAFS, are analyzed by principal component analysis (PCA) (Wasserman, 1997; Wasserman et al., 1999; Ressler et al., 2000; Manceau et al., 2002a). This statistical method allows one to estimate the number of individual species, and to identify their nature from a library of model compounds. Once all the unknown species have been identified, their proportions in the whole substrate can be determined by least-squares fitting of the bulk average EXAFS spectrum with a linear combination of the identified component spectra.

In the present work, this combined approach was used to investigate the effects of phytostabilization on the speciation of $\mathrm{Zn}$ in a contaminated dredged sediment. Scanning electron microscopy interfaced with an energy dispersive spectrometer (SEM-EDS) and synchrotron-based X-ray fluorescence (SXRF) were used in addition to EXAFS spectroscopy. The application of phytostabilization to metal sulfide-containing sediment is shown to accelerate the formation of oxidized forms. However, the nature of the neoformed oxygenated species was determined mainly by the physico-chemical characteristics ( $\mathrm{pH}$, dissolved anions 
and cations species) of the soil matrix and not by the local geochemical environment in the soil set up by the presence of the plant roots.

\section{MATERIALS AND METHODS}

\subsection{Materials}

\subsubsection{Sampling area and characteristics of the sediment}

The sampling area is located in the north of France, about $30 \mathrm{~km}$ south of Lille. This region is among the oldest and largest smelting area in Europe, and past and present contamination by non-ferrous metal processing has released huge amounts of ore particles and slags into the environment (Thiry and Van Oort, 1999; Thiry et al., 2002). About 1,500 kg of raw sediment were collected in the Scarpe river, sieved $(<2 \mathrm{~cm})$, and protected from rainfalls for three months in order to reduce its water content. During this stage, the sediment was mechanically homogenized several times. The sediment is composed of $68.3 \% \mathrm{SiO}_{2}, 6.9 \%$ $\mathrm{CaO}, 4.8 \% \mathrm{Al}_{2} \mathrm{O}_{3}, 2.4 \% \mathrm{Fe}_{2} \mathrm{O}_{3}$ and $0.7 \% \mathrm{P}_{2} \mathrm{O}_{5}$. Its metal composition and main characteristics are given in Table 1.

\subsubsection{Amendments}

Two inorganic amendments were tested : pure synthetic hydroxylapatite (AP) $\left(\mathrm{Ca}_{10}\left(\mathrm{PO}_{4}\right)_{6}(\mathrm{OH})_{2}\right)$ provided by Brenntag (Germany), and Thomas basic slag (TS) provided by Cedest (France). The purity of AP is certified to $99 \%$ by the supplier, and the particle size is about $7 \mu \mathrm{m}$. TS is a by-product of the steel industry, and is used as a phosphorus fertilizer. In acidic soils, the phosphorous availability from TS is similar to that of other phosphorus 
fertilizers (Sinaj et al., 1994). The TS slag particles have a $<50 \mu \mathrm{m}$ size and are composed of of a P, Si and Ca porous matrix encapsulated in an Fe, Ca and Mg material (Sinaj et al., 1994). The TS amendment used in this study contains $37.8 \% \mathrm{CaO}, 2.8 \% \mathrm{Al}_{2} \mathrm{O}_{3}, 14.4 \% \mathrm{Fe}_{2} \mathrm{O}_{3}, 10.6$ $\% \mathrm{SiO}_{2}, 1.9 \% \mathrm{MgO}, 1.6 \mathrm{MnO}_{2}$, and $1.2 \% \mathrm{P}_{2} \mathrm{O}_{5}$. Spannagel et al. (1997) showed that TS contains the following crystalline phases : larnite-type $\left(\beta-\mathrm{Ca}_{2} \mathrm{SiO}_{4}\right)$ calcium silico-phosphate containing $\mathrm{P}_{2} \mathrm{O}_{5}$, calcium ferrite $\left(\mathrm{Ca}_{2} \mathrm{Fe}_{2} \mathrm{O}_{5}\right)$ containing nano-domains of $\mathrm{Al}_{2} \mathrm{O}_{3}$ and $\mathrm{TiO}_{2}$, wustite $(\mathrm{FeO})$ containing $\mathrm{Mg}$ and $\mathrm{Mn}$, lime, and magnetite. This mineral composition was verified by X-ray diffraction (data not shown).

\subsubsection{Preparation and characterization of Zn-reacted AP and TS references}

Since the objective was to obtain surrogates for the possible interaction mechanisms of Zn with AP and TS in the sediment, Zn aliquots were added to AP and TS suspensions at varying $\mathrm{pH}$ and in under to near saturation with respect to the known crystalline solids (hopeite, scholzite, tarbuttite, spencerite). Three AP suspensions $\left(0.5 \mathrm{~g} \mathrm{~L}^{-1}\right)$ were adjusted to

pH 6, 7 and 7.8 with a pH-stat using $10^{-2}$ or $10^{-3} \mathrm{~mol} \mathrm{~L}^{-1} \mathrm{HNO}_{3}$ solution. Continuous degassing with $\mathrm{N}_{2}$ prevented $\mathrm{CO}_{2(\mathrm{~g})}$ intrusion and consequent formation of carbonate ions. After $12 \mathrm{~h}$ equilibration time at constant $\mathrm{pH},[\mathrm{Ca}]_{\mathrm{aq}}$ and $[\mathrm{P}]_{\mathrm{aq}}$ were, respectively, 700 and $435 \mu \mathrm{mol} \mathrm{L} \mathrm{L}^{-1}$ at pH 6, 88 and $64 \mu \mathrm{mol} \mathrm{L}^{-1}$ at $\mathrm{pH} 7$, and 48 and $47 \mu \mathrm{mol} \mathrm{L}^{-1}$ at $\mathrm{pH}$ 7.8. The $[\mathrm{Ca}]_{\mathrm{aq}} /[\mathrm{P}]_{\mathrm{aq}}$ molar ratio decreased with increasing $\mathrm{pH}$ from $1.60(\mathrm{pH} 6)$ to $1.38(\mathrm{pH} 7)$ to $1.02(\mathrm{pH} 7.8)$. This increasing deviation from the stoichiometric $\mathrm{Ca} / \mathrm{P}$ ratio of 1.67 for hydroxylapatite may arise from the re-adsorption of $\mathrm{Ca}$ or the preferential release of $\mathrm{P}$ at increasing $\mathrm{pH}$. Precipitation of another phase (e.g., carbonates) is excluded in the conditions of our experiment. The solution was undersaturated with respect to precipitation of other $\mathrm{Zn}$ (e.g., carbonates and hydroxides) or P phases. Then, $78 \mu \mathrm{mol} \mathrm{L}{ }^{-1} \mathrm{Zn}(\mathrm{II})$ was added to each batch with the solution $\mathrm{pH}$ maintained constant. Following $\mathrm{Zn}$ addition, the aqueous $\mathrm{Ca} / \mathrm{P}$ ratio changed to $1.73(\mathrm{pH} 6), 2.10(\mathrm{pH} 7)$ 
and $2.13(\mathrm{pH} 7.8)$ after $48 \mathrm{~h}$ reaction time, while $[\mathrm{Zn}]_{\mathrm{aq}}$ decreased to $6.95 \mu \mathrm{mol} \mathrm{L}^{-1}$ (pH 6), 5.7 $\mu \mathrm{mol} \mathrm{L} \mathrm{L}^{-1}$ (pH 7), and $1.85 \mu \mathrm{mol} \mathrm{L}{ }^{-1}$ (pH 7.8). The concomitant increase of the $\mathrm{Ca} / \mathrm{P}$ ratio and $[\mathrm{Zn}]_{\mathrm{aq}}$ decrease with $\mathrm{pH}$ subsequent to $\mathrm{Zn}$ addition may be explained by $\mathrm{Zn}$-phosphate precipitation or by $\mathrm{Zn}$ for Ca surface exchange at the hydroxylapatite surface. This first uptake mechanism is likely at $\mathrm{pH} 7$ and 7.8 because in these conditions the $\mathrm{Zn}$ concentration was at near-saturation with respect to hopeite and scholzite (Table 2) : $7.4 \mu \mathrm{mol} \mathrm{L}-1$ and $6.9 \mu \mathrm{mol} \mathrm{L} \mathrm{L}^{-1}$, respectively, at $\mathrm{pH} 7,2.2 \mu \mathrm{mol} \mathrm{L}^{-1}$ and $1.4 \mu \mathrm{mol} \mathrm{L}{ }^{-1}$, respectively, at $\mathrm{pH}$ 7.8. At $\mathrm{pH}$ 6, the $\mathrm{Ca} / \mathrm{P}$ ratio was still close to the stoichiometric ratio in apatite, and $[\mathrm{Zn}]_{\mathrm{aq}}$ was below the solubility limit of hopeite $\left.(27 \mu \mathrm{mol} \mathrm{L})^{-1}\right)$ and scholzite $(23 \mu \mathrm{mol} \mathrm{L}-1)$. The solution was more undersaturated relative to the more soluble tarbuttite and spencerite phases (Table 2). Thus, at this $\mathrm{pH}$ a significant fraction of $\mathrm{Zn}$ probably sorbed or exchanged for $\mathrm{Ca}$ on the AP surface and not precipitated. Finally, Zn-reacted AP and TS references (henceforth denoted by the codenames $\mathrm{ZnPhos}$ and $\mathrm{ZnTS}$ ) were prepared in the same conditions as before but at $\mathrm{pH} 5$ to exclude as much as possible $\mathrm{Zn}$ precipitation. After $48 \mathrm{~h}$ equilibration, all suspensions were centrifuged, freeze-dried, and pressed as pellets for powder EXAFS measurements.

\subsubsection{Pot experiment}

Festuca rubra (FR) and Agrostis tenuis (AT), two graminaceous plants known to be metal-tolerant and to store metals preferentially in roots rather than in aerial parts, were used in this study. Seeds of FR and AT were sown separately in plastic pots filled with $40 \mathrm{~kg}$ of either the untreated sediment (S), the sediment amended with $3 \mathrm{wt}$ \% AP (SAP), or the sediment amended with 5 wt. \% TS (STS; sample names are listed in Table 3). Nine pots (two plants x three substrates plus three unvegetated substrates) were placed in a greenhouse without artificial lighting, and daily irrigated with tap water in an amount similar to the mean rainfall in northern France. The $\mathrm{pH}$ of the pore water was measured every three weeks. After two years of 
culture, the pots were dismantled to collect samples. In vegetated pots, the texture and color of the sediment in areas colonized by the roots (first $30 \mathrm{~cm}$ of the pots) were similar to a brown silty soil, whereas the initial sediment was black and compact. Undisturbed blocks of substrates were collected at about $15 \mathrm{~cm}$-depth in vegetated and non-vegetated pots. One part of the blocks was freeze-dried, embedded in epoxy resin, cut as $30 \mu \mathrm{m}$-thick thin sections, micropolished and mounted on glass slides. The other part was freeze-dried, sieved to remove the roots, ground and pressed as pellets for EXAFS measurements.

\subsection{Methods}

Sediment samples were dissolved and elemental concentrations were measured by inductively coupled plasma atomic emission spectroscopy (ICP-AES, Jobin-Yvon, JY 138 ultrace) as described in Isaure et al. (2002). Thin sections of the substrates were coated with carbon and examined by scanning electron microscopy (Hitachi s-3500N) interfaced with an X-ray microanalyzer (Link Isis 300) (SEM-EDS). Zn-rich regions were searched automatically by scanning the sample under the electron beam and monitoring the XY positions with Gunshot software (Link Isis 300). This instrument enabled us to analyze the chemical composition of $\mathrm{Zn}$-rich spots down to $\mathrm{Z}=5$. The same thin sections were examined on beamline 10.3.2 at the Advanced Light Source (ALS, Berkeley, USA) for $\mu$-SXRF and $\mu$ EXAFS analysis (Marcus et al., 2004). The beam was monochromatized with a pair of Si (111) crystals and focused to 5 x $5 \mu \mathrm{m}$ FWHM with Kirkpatrick-Baez (KB) mirrors. Thin sections were mounted vertically and oriented at $45^{\circ}$ from the incident beam, and the X-ray fluorescence was measured with a 7-element Ge detector. $\mu$-SXRF coarse maps were recorded first to relocate the Zn-rich regions previously identified by SEM-EDS. Then, $\mu$-SXRF fine maps were recorded over $500 \times 500 \mu \mathrm{m}$ areas in the different regions-of-interest in $5 \times 5 \mu \mathrm{m}$ steps with $500 \mathrm{~ms}$ dwell time, and an incident energy of $10 \mathrm{KeV}$. Points-of-interest were 
selected from chemical maps and point $\mu$-EXAFS spectra recorded in fluorescence-yield detection mode. Al foils were used to reduce the background fluorescence of elements lighter than $\mathrm{Zn}$, which would otherwise saturate the detector. Depending on Zn concentration, four to twenty scans of 30 minutes each were recorded and averaged at each spot analyzed.

Zn K-edge EXAFS spectra of powder samples were recorded on the FAME spectrometer (BM 30B) at the European Synchrotron Radiation Facility (ESRF, Grenoble, France) in fluorescence detection mode. The spectrometer is equipped with a first mirror for collimation and heat load attenuation, a two-crystal Si (111) monochromator with dynamical sagittal focusing (Hazemann et al., 1995), and a downstream mirror for vertical focusing and harmonic rejection. Fluorescence-yield EXAFS spectra were measured with a Canberra 30element Ge detector, and the same background fluorescence removal and scan-averaging procedures as for $\mu$-EXAFS measurements were followed.

Bulk and $\mu$-EXAFS spectra were analyzed according to the procedure described in Manceau et al. (2002a). The whole set of $\mu$-EXAFS spectra was treated first by principal components analysis (PCA). The number of principal components (i.e., Zn chemical species) was evaluated statistically with the IND indicator, whose value is nominally a minimum for the number of components needed. The higher the number of $\mu$-EXAFS spectra and the wider the fractional range of the various metal species in the set of spectra, the more reliable is this species counting method. Thirty-two $\mu$-EXAFS spectra were processed from spots whose chemical composition, as assessed from point SXRF and EDS measurements, varied quite continuously between S-rich, Si-rich and P-rich poles. This purely statistical approach was tested by visual comparison of the experimental and reconstructed spectra using a limited number of components. Then, $\mathrm{Zn}$ chemical species were identified by target transformation. In this operation, spectra from a library of model compounds are decomposed in the orthogonal base of principal components. If the transformed and initial spectra are alike, then the tested species is considered potentially present in the unknown sample. Since only the species present 
in the library of model compounds can be identified, this library ought to be as large as possible. We used the extended inorganic and organic Zn libraries described in Sarret (1998) and Manceau et al. (2003), completed by ZnPhos and ZnTS samples. Finally, once Zn species were identified, their proportions in bulk samples and in the analyzed spots were determined by least-squares fitting (LSF) of experimental spectra to linear combinations of the reference spectra. Note that the unknown spectra can be meaningfully reconstructed only if all the predominant $\mathrm{Zn}$ species were identified beforehand by target transformation. If a major species is absent from the database, then the spectral reconstruction fails. The quality of the fit was quantified by the residual $R$ parameter:

$$
R=\Sigma\left|k^{3} \chi_{\exp }-k^{3} \chi_{\text {model }}\right| / \Sigma\left|k^{3} \chi_{\exp }\right|
$$

Previous studies showed that the precision in the proportion of individual species is about $10 \%$ of the total amount of Zn (Isaure et al., 2002; Manceau et al., 2002b).

\section{RESULTS}

\subsection{Identification of Zn species at the micrometer scale}

Of the thirty-two $\mu$-EXAFS spectra recorded, thirty-one exhibit spectral features which are found in other spectra, which indicates a finite number of $\mathrm{Zn}$ species that are present in variable proportions from one spot to another. The thirty-one spectra can be classified in three groups (herein referred to as type I, II and III) on the basis of their shape, suggesting the occurrence of three dominant families of Zn species (Fig. 1).

\subsubsection{Pure Zn species}


The one spectrum differing from all the others was well-fitted with $67 \%$ gahnite ( $\mathrm{ZnAl}_{2} \mathrm{O}_{4}$, Fig. 2). The percentage of $\mathrm{Zn}$-rich species estimated from fluorescence-yield EXAFS is systematically underestimated owing to an over-absorption effect (Manceau et al., 2002a). The abundance of $\mathrm{Zn}$ at this particular point of analysis was confirmed by X-ray fluorescence, which showed an intense $\mathrm{Zn} \mathrm{K \alpha}$ line. Gahnite is a spinel produced by smelters using pyro-metallurgical processes (Thiry and Van Oort, 1999; Thiry et al., 2002). The spectrum I \# 3 is reproduced with $76 \%$ sphalerite (ZnS, Fig. 3). Again, the effective percentage of this pure $\mathrm{Zn}$ species differs from $100 \%$ because of over-absorption in the sample. As expected for a high $\mathrm{Z}$ element-containing grain, the analyzed spot appears bright in SEM imaging with backscattered electrons, and the presence of both $\mathrm{Zn}$ and $\mathrm{S}$ was confirmed by EDS analysis (Fig. 3C). This mineral is the main Zn species of type I spectra. The presence of sphalerite in Zn-contaminated sediments was reported previously (O'Day et al., 1998; Webb et al., 2000; Scheinost et al., 2002), and in particular in the Scarpe river sediment in which sphalerite grains were found in black slags and vitreous grains originating from the nearby smelters (Isaure et al., 2002).

The last single-component $\mu$-EXAFS spectrum of the series is spectrum II \# 2. This spectrum, and therefore its radial structure function (RSF), are almost identical to the Zn-rich phyllosilicate reference $\mathrm{Si}_{4}\left(\mathrm{Zn}_{2.1} \mathrm{Mg}_{0.9}\right) \mathrm{O}_{10} \cdot \mathrm{nH}_{2} \mathrm{O}$ (ZnKer210) (Fig. 4). Since in trioctahedral 2:1 phyllosilicates $\mathrm{Zn}$ and $\mathrm{Mg}$ form a solid solution, the stoichiometry of the soil $\mathrm{Zn}$ phyllosilicate was evaluated by testing references having various $\mathrm{Zn} / \mathrm{Mg}$ ratios. $\mathrm{Si}_{4} \mathrm{Zn}_{3} \mathrm{O}_{10} \cdot \mathrm{nH}_{2} \mathrm{O}(\mathrm{ZnKer} 300)$ and particularly $\mathrm{Si}_{4}\left(\mathrm{Zn}_{0.03} \mathrm{Mg}_{2.97}\right) \mathrm{O}_{10} \cdot \mathrm{nH}_{2} \mathrm{O}(\mathrm{ZnKer} 003)$ gave poorer matches to the data, in particular at 5.5, 7.4 and 8.2 $\AA^{-1}$ (see arrows in Fig. 4a). The phyllosilicate precipitate is rich in $\mathrm{Zn}$, but may contain some $\mathrm{Mg}$ atoms in its octahedral sheet. $\mathrm{Zn}$-phyllosilicate is the dominant $\mathrm{Zn}$ species for the type II spectra. This species has been detected by EXAFS spectroscopy in the clay fraction of soils (Manceau et al., 2000; Scheinost et al., 2002; Manceau et al., 2004; Isaure et al., 2005), and also in the Scarpe sediment (Isaure 
et al., 2002). In all these studies, it was always mixed with other $\mathrm{Zn}$ species in the analyzed sample volume and the EXAFS spectrum of this component was never obtained separately. This result provides the first direct and unequivocal evidence for the presence of $\mathrm{Zn}$-rich, kerolite-like, trioctahedral phyllosilicate in a minimally perturbed natural matrix, and serves as an excellent demonstration of the capability of this new laterally resolved $\mu$-EXAFS spectroscopic tool.

\subsubsection{Zn species present in admixtures}

Although several analyzed spots contain pure $\mathrm{Zn}$ phases, most spots are mixtures of $\mathrm{Zn}$ species. The number of principal components is six as estimated from the IND parameter of PCA. However, several type II and III spectra were not reconstructed satisfactorily with six components, and ten components (Fig. 5) proved necessary to reproduce all thirty-two $\mu$ EXAFS spectra. As expected, sphalerite, gahnite and Zn-rich phyllosilicate spectra are well reconstructed since these occur as solitary species in some spots. Among the Zn-phyllosilicates available in our database, the best target transformation overall was obtained with ZnKer210 $\left(\mathrm{Si}_{4}\left(\mathrm{Zn}_{2.1} \mathrm{Mg}_{0.9}\right) \mathrm{O}_{10} \cdot \mathrm{nH}_{2} \mathrm{O}\right)$. The spectrum of the $\mathrm{Zn}$ end-member $\left(\mathrm{Si}_{4} \mathrm{Zn}_{3} \mathrm{O}_{10} \cdot \mathrm{nH}_{2} \mathrm{O}\right)$ also was well reproduced by target transformation (data not shown). In contrast, the quality of the reconstruction dropped rapidly when the amount of $\mathrm{Mg}$ in the octahedral layer of the phyllosilicate was increased. In particular, target testing of $\mathrm{Si}_{4}\left(\mathrm{Zn}_{1.3} \mathrm{Mg}_{1.7}\right) \mathrm{O}_{10} \cdot \mathrm{nH}_{2} \mathrm{O}$ (ZnKer130) was unsatisfactory, and even more so for $\mathrm{Si}_{4}\left(\mathrm{Zn}_{0.3} \mathrm{Mg}_{2.7}\right) \mathrm{O}_{10} \cdot \mathrm{nH}_{2} \mathrm{O}(\mathrm{ZnKer030})$. Our analysis demonstrates that the sediment phyllosilicate is rich in $\mathrm{Zn}$ and has a relatively narrow chemical variability. Of all the Zn-reacted hydroxylapatite references, only ZnPhos and ZnTS, whose spectra are quite similar, were well reconstructed. Hopeite $\left(\mathrm{Zn}_{3}\left(\mathrm{PO}_{4}\right)_{2} \cdot 4 \mathrm{H}_{2} \mathrm{O}\right)$ yielded a slightly poorer spectral match, though still acceptable. (Zn,Al)-hydrotalcite (ZnHyd) was well reproduced too, but its spectrum is close to that of ZnKer210. Of the various Fe 
(oxyhydr)oxides tested, the best spectral match was obtained with $\mathrm{Zn}$-sorbed ferrihydrite (ZnFh), followed by Zn-sorbed goethite (ZnGoet). The original and reconstructed franklinite $\left(\mathrm{ZnFe}_{2} \mathrm{O}_{4}\right)$ spectra have a similar shape, but the amplitudes of the oscillations are imperfectly reproduced because this species was always present in subordinate amounts in the analyzed spots. In summary, target testing against $\mathrm{Zn}$ references identified four additional good candidates (Zn-phosphate, Zn-ferrihydrite, $(\mathrm{Zn}, \mathrm{Al})$-hydrotalcite, franklinite), in addition to the three firm species previously identified (sphalerite, gahnite, Zn-rich kerolite).

The occurrence of the new species was verified by fitting all multi-component spectra to the minimum number of inferred species. Adding a new component species in the spectral fit was allowed if its addition improved the fit visually. In most cases, adding a 'good' component decreased $R$ by at least $10 \%$. All multi-component spectra were successfully reproduced with two, three or four references. A selection of fits is presented in Figure 6. The spectrum I \# 1 (sphalerite-type) was improved by $\sim 30 \%$ when $\mathrm{Zn}$-ferrihydrite was added to $\mathrm{ZnS}$, and again by $\sim 12 \%$ upon adding gahnite (Fig. 6a). The $\mathrm{ZnFh}-\mathrm{ZnS}$ association has been described in other studies and results from the partial oxidation of metal sulfides $(\mathrm{ZnS}$ and $\mathrm{FeS})$ in oxic environments (O'Day et al., 1998; Isaure et al., 2002). Adding gahnite (reference spectrum in Fig. 2) allowed matching of the peak at $\sim 8.2 \AA^{-1}$. The spectrum II \# 5 exhibits a series of four successive resonances at 5.3, 6.2, 7.0 and $7.3 \AA^{-1}$, which are characteristic of franklinite (Fig. $6 b)$. However, spectral simulation showed that this species accounts for only $\sim 20 \%$ of total $\mathrm{Zn}$, the major species in this sample spectrum being $\mathrm{ZnFh}$. The sensitivity to franklinite is due to the high amplitude and multiple wave frequencies of the EXAFS spectrum for this mineral, which has a well-ordered and symmetrical structure and contains two strong X-ray scatterers ( $\mathrm{Zn}$ and $\mathrm{Fe}$ ). Therefore, the occurrence of franklinite, which was inferred from target transformation, is confirmed. ZnPhos (or ZnTS) was detected in many analyzed spots, but in differing proportions. Some $\mathrm{ZnPhos}$ regions corresponded to diffuse $\mathrm{Zn}$ concentrations within the sediment matrix (e.g., spectrum III \# 1, Fig. 6c) and others to localized higher Zn areas 
(e.g., spectrum II \# 4, Fig. 7). The occurrence of Zn-phosphate is supported by the detection of $\mathrm{P}$ in the EDS analysis (Fig. 7b), and the observed P-Zn correlation on the EDS spectrum when the sample was moved by a few tens of micrometers off the Zn-P spots. ZnFh and ZnPhos were often detected together in the sediment matrix, and we consider that they are 'background' species, which are present almost everywhere. Zn-goethite, hopeite, and low-Zn phyllosilicate never appeared in the spectral simulations.

Figure 8 compares the two best simulations for spectrum II \# 7, obtained with either hydrotalcite (ZnHyd) or high-Zn phyllosilicate (ZnKer210) as major species, and Zn-phosphate (ZnPhos) as minor species. Since the presence of high-Zn phyllosilicate does not exclude the occurrence of $(\mathrm{Zn}, \mathrm{Al})$-hydrotalcite, this latter species needs to be evaluated carefully. The similarity of the two-component spectral simulations results from the similarity of the local structure of $\mathrm{Zn}$ in $\mathrm{Zn}$-rich phyllosilicate (here kerolite is used as a proxy for the general class of high-Zn phyllosilicate) and (Zn,Al)-hydrotalcite (Fig. 9). Both compounds have an octahedral sheet in which $\mathrm{Zn}$ is surrounded by approximately the same proportion of 'heavy' $(\mathrm{Zn})$ and 'light' $(\mathrm{A} 1, \mathrm{Mg})$ atoms at about the same distance $(3.05-3.10 \AA)$. The two reference spectra mainly differ in the $5.0-5.5 \AA^{-1}$ interval with phyllosilicate exhibiting a well-resolved resonance at $\sim 5.2 \AA^{-1}$ while a shoulder is observed on the hydrotalcite spectrum (Fig. 10a). Schlegel et al. (2001) showed by polarized-EXAFS (P-EXAFS) that this resonance is angulardependent, and originates from the contribution of $(\mathrm{Si}, \mathrm{Al})$ cations in the tetrahedral sheets of phyllosilicates. This assignment is supported experimentally in P-EXAFS by the observation that the resonance smears out and resembles that in hydrotalcite when the contribution from the tetrahedral sheet is minimized (almost cancelled) and, alternatively, the contribution from the octahedral sheet maximized, in the in-plane orientation. In addition, the next-nearest Si shell (Si2 shell) at $4.4-4.5 \AA$ and higher oxygen shells generate the third peak observed on the RSF of Zn-rich phyllosilicate at $R+\Delta R \sim 3.5-4.0 \AA$ (Manceau et al., 1998). This peak is obviously absent in (Zn-Al)-hydrotalcite (Manceau et al., 1999) (Fig. 10b). Consequently, the occurrence 
of an oscillation at $\sim 5.2 \AA^{-1}$ and of a specific Fourier transform signature at about $3.5-4.0 \AA$ are indicative of $\mathrm{Zn}$ phyllosilicate. In contrast to $\mathrm{Zn}$-rich phyllosilicate, the spectra for low-Zn and pure-Zn phyllosilicates are dissimilar to hydrotalcite because in the low- $\mathrm{Zn}$ phase $\mathrm{Zn}$ is surrounded only by 'light' atoms and in the high-Zn phase only by 'heavy' atoms in the octahedral sheet.

Returning to the experimental data in Figure 8, the two diagnostic features of phyllosilicate at $\sim 5.2 \AA^{-1}$ in $k$ space and at $\sim 3.5-4.0 \AA$ in real space are absent from spectrum II \# 7. So, fitting this spectrum with phyllosilicate resulted in a poor spectral match in the two indicator regions. Consequently, this analysis shows that hydrotalcite is really present in the sediment sample. The occurrence of (Zn,Al)-hydrotalcite was inferred from a complex multishell fit analysis of a Fourier filtered EXAFS spectrum for a chemically treated soil sample (Juillot et al., 2003). In the present study, the use of $\mu$-EXAFS spectroscopy, complemented by PCA and the availability of an extended database of appropriate reference species, offers direct and unambiguous evidence for the existence of this species in nature.

\subsubsection{Conclusion on the micro-analysis of the sediment thin sections}

The large number of experimental spectra analyzed here by PCA offers an opportunity to assess the validity of the IND indicator used to estimate the number of metal species in a heterogeneous system. The IND parameter was minimum when the number of principal components used to reconstruct the thirty-two experimental EXAFS spectra was equal to six. Visual inspection of the experimental and reconstructed spectra using a combination of the first five, six and seven components confirmed that six orthogonal components were necessary and sufficient to reconstruct the whole set of data. In direct contrast with this estimate, target transformation identified ten species whose spectral shapes are different enough to give credence to this value. In keeping with this result, fitting the whole set of individual spectra 
with less than ten species failed. A similar observation was made by Manceau et al. (2002a), who found that the IND parameter indicated one less species than really present in the studied soil because the missed species was uniformly distributed throughout the sample. The same explanation applies here. PCA is a purely statistical method, which decomposes a linear system (i.e., the set of $\mu$-EXAFS spectra) into orthogonal bases (i.e., the principal components). Then, an assumption is made that the number of significant components (evaluated from IND) is equal to the number of species. This assumption is correct if the proportion of each species varies ideally from 0 to 1 in the set of data. This is obviously not the case in natural systems because some phase mixtures are homogeneous at the micrometer scale. Therefore, the limitation comes from the fact that this technique explores a system at a particular scale of heterogeneity and lacks sensitivity to the smaller scale of heterogeneity. Despite this intrinsic limitation, a homogeneous mixture of $\mathrm{Zn}$ species at the micrometer-scale can be resolved by fitting the multi-component $\mu$-EXAFS spectrum with a set of reference spectra previously identified by target transformation. Therefore, the collection of a series of $\mu$-EXAFS spectra can provide information which would not be accessible with a single spectrum, that is with conventional speciation investigation by bulk EXAFS analyses. Application of this novel solidstate speciation technique allowed us to identify seven Zn species: sphalerite, gahnite and franklinite, which are primary minerals of anthropogenic sources, and Zn-containing ferrihydrite and phosphate, Zn-rich phyllosilicate and (Zn,Al)-hydrotalcite, which are secondary minerals. Zn-phosphate precipitates have been observed on the root surface of Agrostis tenuis grown on a contaminated soil amended with phosphate (Cotter-Howells et al., 1999). Zn-rich phyllosilicate and (Zn,Al)-hydrotalcite have been identified or inferred in contaminated soil and sediment from bulk and polarized EXAFS analysis (Manceau et al., 2000; Isaure et al., 2002; Voegelin et al., 2002; Juillot et al., 2003; Manceau et al., 2004), but their existence had never been ascertained directly by micrometer-scale analysis of a natural sample, whose original texture was preserved. 


\subsection{Quantification of Zn species at the macroscopic scale}

Fractional amounts of the seven $\mathrm{Zn}$ species in the bulk samples were determined next by least-squares fitting the powder EXAFS spectra with linear combinations of the EXAFS spectra for each Zn species. The EXAFS spectra of all nine substrates and a selection of Fourier transforms are shown in Figures 11 and 12. The spectra for the control (S) and amended (SAP and STS) sediments are similar and almost in phase with ZnS. The two first oscillations of SAP and STS are larger and the following two less intense relative to the S spectrum. Also, a hump at $8.2 \AA^{-1}$ is observed in the amended sample spectra. These spectral evolutions are more marked in STS than in SAP. The spectra for all the vegetated substrates are almost superimposed, which means that amendments did not modify significantly the $\mathrm{Zn}$ speciation. The whole set of bulk spectra clearly belongs to a pseudobinary system, in which one end-member is the $\mathrm{S}$ spectrum and the other is the vegetated sample spectra. The observed spectral evolution can be rationalized by conjecturing that plants and amendments decreased the proportion of a pre-existing $\mathrm{Zn}$ species and concomitantly either induced the formation of a new species or increased the amount of a pre-existing species. The shift in frequency of the treated sample spectra relative to the initial (S) spectrum is consistent with replacement of sulfur by oxygen ligands in the Zn coordination sphere, as demonstrated in Figure 12 by the progressive shift to lower distance of the first RSF peak. All these observations suggest that, (1) $\mathrm{ZnS}$ is the predominant $\mathrm{Zn}$ species in $\mathrm{S}$, (2) the amendments induced a limited oxidation of $\mathrm{ZnS}$, and (3) plants increased the extent of $\mathrm{ZnS}$ oxidation. The fact that the vegetated sample spectra are independent of the presence of amendment indicates that the effect of plants prevails over the effect of amendments. In the next section, spectral simulations will be performed to determine whether the disappearance of $\mathrm{ZnS}$ is accompanied by the formation of a new Zn species. 


\subsubsection{Simulation of bulk EXAFS spectra by LSF}

The S spectrum was reproduced satisfactorily with a combination of $\mathrm{ZnS}, \mathrm{ZnFh}$ and $\mathrm{ZnHyd} / \mathrm{ZnKer}$, in proportions of $\sim 50 \%$ (mole ratio of total $\mathrm{Zn}$ ), $40 \%$ and $10-20 \%$, respectively (estimated accuracy $10 \%$ of the total Zn) (Fig. 13). Adding a fourth component did not improve significantly the fit quality. The two simulations obtained with either ZnHyd or ZnKer210 gave similar results $(R=0.21$ and $R=0.24$, respectively). As discussed previously, differentiating these two species is difficult in a mixture, and even more so when they are minor components ( $\sim 16$ and $12 \%$, respectively). Here, the best fit will be retained, and this pool will be referred to as "ZnKer/ZnHyd". The amended sediments (SAP and STS) contain less $\mathrm{ZnS}$ ( $\sim 40$ and $30 \%$, respectively) and $\mathrm{ZnFh}(\sim 20 \%)$ than the untreated sediment (S sample), but contain ZnPhos ( 30-40\%) (Fig. 14 and 15). The ZnKer/ZnHyd fraction is almost constant $(\sim 15-20 \%$ of total $\mathrm{Zn})$. These results indicate that the addition of AP or TS amendments favored the formation of $\mathrm{ZnPhos}$ at the expense of $\mathrm{ZnS}$ and $\mathrm{ZnFh}$.

In the vegetated pots, the proportion of $\mathrm{ZnS}$ ranges from 0 to $\sim 10 \%$, depending on the sample. This amount can be approximated as zero as the upper value is comparable to the uncertainty. Supporting evidence for the oxidation of $\mathrm{ZnS}$ comes from the detection of gypsum $\left(\mathrm{CaSO}_{4}\right)$ in the vegetated sediment samples by X-ray diffraction (data not shown). The ZnPhos and $\mathrm{ZnKer} / \mathrm{ZnHyd}$ pools are more abundant in the presence of plants ( 40-60\% and $\sim 20-40 \%$, respectively), and the proportion of $\mathrm{ZnFh}$ is not significantly different from the SAP and STS samples $(\sim 20 \%)$. Thus, plants increased the oxidation rate of $\mathrm{ZnS}$, and $\mathrm{Zn}$ released in the sediment solution was predominantly immobilized as $\mathrm{ZnPhos}$ and $\mathrm{ZnKer} / \mathrm{ZnHyd}$. These variations in the relative proportions of $\mathrm{Zn}$ species truly correspond to a redistribution of $\mathrm{Zn}$ among different phases because the total concentration of $\mathrm{Zn}$ remained constant in all the experiment pots. This was verified by monitoring the composition of solutions collected at the 
bottom of the pots, which showed that less than $0.2 \%$ of total $\mathrm{Zn}$ was leached out (Bert et al., 2003), and also by measuring the amount of $\mathrm{Zn}$ exported into the plants, which was negligible relative to the amount of metal in the substrates.

\subsubsection{Conclusion of the analysis of the bulk samples}

Of the seven Zn species detected at the micrometer scale, two of them (gahnite and franklinite) were not detected by bulk analysis. The control sediment (S) contains mainly sphalerite, and also $\mathrm{ZnFh}$ and $\mathrm{ZnKer} / \mathrm{ZnHyd}$ that presumably result from the weathering of sphalerite after the sediment dredging. These same species are present in all the treated sediment samples but in variable proportions, and a new species, modeled by the ZnPhos reference, is present. In order to test the idea that the bulk samples could be understood as pseudobinary mixtures, PCA was performed on the table of compositions shown in Figure 14. We considered each set of four fractions (of $\mathrm{ZnS}, \mathrm{ZnFh}, \mathrm{ZnPhos}$, and $\mathrm{ZnKer} / \mathrm{ZnHyd}$ ) as a "spectrum" and asked how best to represent them as weighted sums of two basis "spectra". All compositions could be reproduced to better than $10 \%$ (maximum error in any fraction) using the following compositions for the end-members:

Mixture 1: 4\% ZnS, 12\% ZnFh, 52\% ZnPhos, 32\% ZnKer/ZnHyd

Mixture 2: 55\% Zns, 36\% ZnFh, 0\% ZnPhos, 9\% ZnKer/ZnHyd.

These component compositions were derived by taking linear combinations of the abstract components delivered by the PCA program, such that neither component had a negative fraction of any of the four reference compounds, and such that the amount of Mixture 2 in the vegetated soil was around zero and not highly negative. The results of this fit are shown in Table 4.

In the sediments amended with AP or TS, one third to one half of the sphalerite was oxidized, the proportion of $\mathrm{ZnFh}$ decreased relative to the control pot, and $\mathrm{ZnPhos}$ was formed. 
In vegetated pots, the sphalerite oxidation was almost completed and $\mathrm{ZnPhos}$ became the main Zn phase followed by ZnKer/ZnHyd. The Zn speciation was independent of the plant species, and the effect of plants on $\mathrm{ZnS}$ oxidation was stronger than the effect of amendments. In addition, there is no cooperative effect between plants and amendments on $\mathrm{ZnS}$ oxidation because the addition of amendments to the vegetated pots did not hasten the oxidation of $\mathrm{ZnS}$.

\section{DISCUSSION}

\subsection{Effect of amendments on Zn speciation}

The amendments accelerated the oxidation of sphalerite and modified the speciation of $\mathrm{Zn}$ in secondary phases. The chemical characteristics of TS and AP help understand the transformation of $\mathrm{Zn}$ speciation. For TS, the lime contained in this material can increase the $\mathrm{pH}$ and, hence, facilitate $\mathrm{Zn}$ immobilization by precipitation and co-precipitation of metal(oxyhydr)oxides (Dimitrova and Mehanjiev, 2000; Knox et al., 2001), and sorption or complexation on inorganic or organic constituents. The iron phases present in TS (calcium ferrite, wustite, and magnetite) can be weathered to Fe-(oxyhydr)oxides, thereby increasing the overall sorption capacity of the sediment. Finally, the release of phosphorous by TS can lead to the precipitation of metal-phosphate. The $\mathrm{pH}$ increased slightly at the beginning of the experiment ( $0.5 \mathrm{pH}$ unit), and then returned to the values measured in the other pots, which were between 6.5 and 7.5 (Bert et al., 2003). Therefore, this parameter alone likely does not explain the observed effects. The second possibility can be disregarded also because the proportion of Zn-sorbed ferrihydrite is lower in the TS-treated sediment than in the control. Note that this was also the case for the other amended and vegetated pots. The reason for this depletion is unclear. The third mechanism is the most likely because the formation of $\mathrm{Zn}$ phosphate upon addition of TS has been demonstrated without ambiguity. The exact nature of 
this Zn-phosphate could not be established precisely, but the featureless shape of its EXAFS spectrum suggests that this phase is a Zn-sorption surface complex or a poorly crystalline $\mathrm{Zn}$ phosphate precipitate. To our knowledge, the formation of a Zn-phosphate species from phosphorous contained in TS slag is documented here for the first time, and it provides a molecular-scale understanding of the mechanism by which this slag material can reduce the mobility of metals in amended natural matrices.

In contrast to TS, the AP amendment consists of a pure phosphate mineral and, therefore, the formation of $\mathrm{Zn}$-phosphate was expected. The precipitation of sparingly soluble $\mathrm{Pb}$-phosphates, namely $\mathrm{Pb}$ hydroxy- and chloro-pyromorphite $\left(\mathrm{K}_{\mathrm{sp}}=10^{-63.1}\right.$ and $10^{-84.4}$, respectively; Nriagu, 1984), after the addition of AP, has been extensively reported from laboratory experiments under medium to moderately acidic conditions (Ma et al., 1993; Lower et al., 1998; Valsami-Jones et al., 1998; Zhang and Ryan, 1999). The formation in contaminated soils of insoluble lead compounds following AP addition has been suggested (Greman et al., 2001; Seaman et al., 2001) and demonstrated (Laperche et al., 1997; Ryan et al., 2001). Fewer works have been undertaken on other potentially hazardous elements, but the precipitation of metal phosphate compounds (e.g., Ni, Zn, Cd) was suggested from laboratory and field studies (Valsami-Jones et al., 1998; Greman et al., 2001; Seaman et al., 2001), although these compounds are more soluble than $\mathrm{Pb}$-phosphates. When $\mathrm{Zn}^{2+}$ is added to AP suspension, laboratory experiments showed that this element reacts with AP or the solute species resulting from its dissolution (Xu and Schwartz, 1994; Peaudecerf, 2002), as confirmed in this study (see section 2.1.3). The formation of hopeite $\left(\mathrm{Zn}_{3}\left(\mathrm{PO}_{4}\right)_{2} \cdot 4 \mathrm{H}_{2} \mathrm{O}\right)$ (Fuierer et al., 1994; Lusvardi et al., 2002), scholzite $\left(\mathrm{CaZn}_{2}\left(\mathrm{PO}_{4}\right)_{2} \cdot 2 \mathrm{H}_{2} \mathrm{O}\right)$ (Lusvardi et al., 2002) and the analogous version of libethenite with $\mathrm{Zn}$ substituting for $\mathrm{Cu}\left(\mathrm{Zn}_{2}\left(\mathrm{PO}_{4}\right) \mathrm{OH}\right)$ (Misra and Bowen, 1981) were documented as reaction products between dissolved $\mathrm{HPO}_{4}{ }^{3-}$ from $\mathrm{AP}$ and solution $\mathrm{Zn}^{2+}$. The nature of the neoformed $\mathrm{Zn}$-phosphate depends on the ion activities in solution, primarily on $\left[\mathrm{Zn}^{2+}\right]_{\mathrm{aq}}$ and $\left[\mathrm{HPO}_{4}{ }^{2-}\right]_{\mathrm{aq}}$, but also $\left[\mathrm{Ca}^{2+}\right]_{\mathrm{aq}}$ since scholzite is a mixed $\mathrm{Ca}-\mathrm{Zn}$ 
phosphate (Fuierer et al., 1994; Xu and Schwartz, 1994) and, in addition, on the proton activity since the dissolution rate of AP is pH-dependent (section 2.1.3, and Valsami-Jones et al., 1998). The formation of $\mathrm{Zn}$-libethenite can be excluded in our case because this mineral was formed in Misra and Bowen's experiments (1981) for Zn concentrations ranging from 3250 to $26000 \mathrm{mg} \mathrm{L}^{-1}$, in excess by three to four orders of magnitude of $\mathrm{Zn}$ concentrations measured in the pore waters (5 to $30 \mathrm{mg} \mathrm{L}^{-1}$ ). The formation of hopeite was ruled out by our EXAFS analysis, and in particular by target transformation of this reference spectrum and the simulation of $\mu$-EXAFS spectra. More generally, the precipitation of a pure Zn-phosphate solid is unlikely according to equilibrium thermodynamic calculations, which show that the large majority of the sediment solutions were undersaturated with respect to the homogeneous precipitation of Zn-phosphate (see last section). Although the exact nature of the Zn-phosphate species is unknown, this work suggests that $\mathrm{Zn}$ reacted with apatite crystallites to form a sorption complex similar to that of our surrogate at $\mathrm{pH} 5$ (i.e., ZnPhos), or possibly a poorly crystalline surface precipitate.

The sediment amended with AP (SAP) is three to four times richer in P than the TS amended sediment (STS), yet the amount of Zn-phosphate is similar in the two pots. This can be explained by the low solubility of hydroxylapatite at the $\mathrm{pH}$ of the sediment in the pot (Valsami-Jones et al. (2001). In contrast, P contained in TS can be readily released from the slag as observed by Martin (1991). As suggested by Laperche et al. (1996), our results indicate that the immobilization of metals by AP can been limited, or even inefficient, when the matrix is neutral or alkaline.

\subsection{Effects of plants on Zn speciation}

The conversion of $\mathrm{ZnS}$ to oxygenated forms was faster in the presence of plants than with the amendments alone. Several processes can be invoked to explain this difference. The 
intrusion of roots in the sediment likely increased dissolved oxygen $\left(\mathrm{P}_{\mathrm{O} 2}\right)$ by increasing the water drainage and aeration of the sediment (Marseille et al., 2000; Bert et al., 2003), due in particular to the absorption of water by roots and plant transpiration. The aeration of the sediment probably prevailed over the effect of root respiration which conversely depletes the rhizosphere (i.e., the volume of soil affected by plant activity) in $\mathrm{O}_{2}$ and enriches it in $\mathrm{CO}_{2}$ (Asady and Smucker, 1989; Marschner, 1995; Hinsinger et al., 2003).

Some micro-organisms, such as Thiobacillus sp., draw their energy from the oxidation of sulfides (Francis et al., 1989; Qureshi et al., 2003); their action on metal mobility was shown on similar sediments (Lors et al., 2004). Since these strains are naturally present in sediments, and because microbial activity is stimulated in the rhizosphere owing to the flux of organic molecules and mineral nutrients, micro-organisms may have contributed to the increase of the ZnS oxidation rate (Bert et al., 2003). Also, plants exude organic molecules, in particular graminaceous plants can exude phytosiderophores (short amino acid chains) to take Fe from minerals (Römheld and Marschner, 1990; Marschner, 1991). Although Fe-deficiency enhances the release of phytosiderophores, studies performed in hydroponic conditions (Römheld and Marschner, 1990; Marschner, 1995) and in the field (Chaignon et al., 2002) showed that these chelates are exuded also under normal nutritional conditions. Since these organic ligands also have a high affinity for Zn (Zhang et al., 1989), their role in $\mathrm{ZnS}$ dissolution is possible.

This study shows that plants direct the formation of $\mathrm{Zn}$ phosphate, and that the addition of P-containing amendments to the vegetated pots does not enhance this effect. This result can be explained by the high $\mathrm{P}$ content of the sediment $(0.7 \%$ compared to an average value of $0.05 \%$ in soils; Lindsay et al., 1989). Two mechanisms can be inferred to account for the higher amount of Zn-phosphate in the presence of plants. We have seen before that plants accelerate $\mathrm{ZnS}$ oxidation and, hence, the release of $\mathrm{Zn}^{2+}$ to solution. Geochemical thermodynamic modeling showed that metal-phosphates act as controlling solids for the equilibrium concentration of $\mathrm{Zn}^{2+}$ in leachates from mine tailings (Eusden et al., 2002). 
Therefore, the enhanced release of $\mathrm{Zn}^{2+}$ from $\mathrm{ZnS}$ by plants may have driven its chemical immobilization by phosphate. According to this mechanism, $\mathrm{ZnS}$ acts as a $\mathrm{Zn}$ donor and phosphate as a $\mathrm{Zn}$ acceptor, with $\mathrm{Zn}$ donation being catalyzed by plants.

The second mechanism involves the dissolution of phosphate minerals initially contained in the sediment by plants. According to this mechanism, plants would have favored the formation of $\mathrm{Zn}$-phosphate by increasing the equilibrium concentration of both $\mathrm{Zn}^{2+}$ and $\mathrm{PO}_{4}{ }^{3-}$ ions into the rhizosphere. Since phosphorous is one of the lowest mobile elements in soils (Hinsinger, 1998), plants have developed active mechanisms to increase its bioavailability, such as the exudation of protons (Bertrand et al., 1999; Neumann et al., 1999) and of organic acids and anions (Marschner, 1995; Zhuang et al., 1997; Neumann et al., 1999). The occurrence of $\mathrm{HPO}_{4}{ }^{2-}$ anions in pore water may also be explained by the instability of phosphate-containing minerals initially present in the sediment. In anoxic sediments, phosphates are often speciated as strengite $\left(\mathrm{FePO}_{4}\left(\mathrm{H}_{2} \mathrm{O}\right)_{2}\right)$ and vivianite $\left(\mathrm{Fe}_{3}\left(\mathrm{PO}_{4}\right)_{2}\left(\mathrm{H}_{2} \mathrm{O}\right)_{8}\right)$ (Berner, 1981; Lindsay et al., 1989; De Rooij and Gerrits, 1995). Ferrous minerals are unstable in oxic environments and the aeration of the sediment in contact with the atmosphere probably contributed to the release of phosphate to solution after the oxidation of ferrous to ferric iron to form oxyhydroxides. As for $\mathrm{ZnS}$, plants may have hastened this oxidation process.

Plants also increased the amount of ZnKer/ZnHyd in the sediment $(\sim 20-40 \%$ compared to $\sim 10-20 \%$ without plants). This phenomenon, which was observed in the six vegetated pots (SAT, SFR, STSAT, STSFR, SAPAT and SAPFR), suggests that plants increased the solution concentration of $\mathrm{Mg}, \mathrm{Al}$ and $\mathrm{Si}$, in addition to $\mathrm{Zn}$. Silicate minerals, whose dissolution rate has been shown to be enhanced by biota (White, 1995; Barker et al., 1998; Banfield et al., 1999), are the main source of $\mathrm{Mg}, \mathrm{Al}$ and Si. The role of plants on mineral dissolution was investigated for plagioclase (Berner, 1995; Bormann et al., 1998; Hinsinger et al., 2001), hordblende (Bormann et al., 1998) and biotite (Hinsinger et al., 1992; Bormann et al., 1998). Laboratory experiments on simplified systems were complemented by 
real world studies of the mineralogy of the rhizosphere (Kodama et al., 1994; Courchesne and Gobran, 1997; Nordborg and Olsson, 1999; Egli et al., 2003). Some mechanisms highlighted by these studies include the depletion of amphibole (Courchesne and Gobran, 1997; Nordborg and Olsson, 1999), the vermiculitization of biotite (Nordborg and Olsson, 1999), and the formation of minute vermiculite particles near and on the root surface (Kodama et al., 1994). These silicates contain essential nutrients for plants, such as $\mathrm{Ca}, \mathrm{Mg}$ and $\mathrm{K}$, and the increase in concentration of $\mathrm{Al}$ and $\mathrm{Si}$ in the rhizosphere can be regarded as a side effect from plant nutrition.

\subsection{Thermodynamic stability of Zn-hydrotalcite, Zn-phyllosilicate and Zn-phosphate}

EXAFS results showed that zinc is present in three solid phases, kerolite-like trioctahedral phyllosilicate, $(\mathrm{Zn}, \mathrm{Al})$-hydrotalcite and phosphate. We now calculate whether the aqueous concentration of $\mathrm{Zn}$ is saturated with respect to these three solids in order to evaluate their formation mechanism, and specifically if they may have precipitated homogeneously in the sediment solution or if heterogeneous precipitation dominated. The possibility of the complexation of $\mathrm{Zn}$ by dissolved organic ligands was not considered in the calculation. If significant, this process would lower the activity of aqueous $\mathrm{Zn}$ and, accordingly, decrease the sursaturation of the solution with respect to all of the phases considered.

The chemical stability of the three $\mathrm{Zn}$ phases was assessed by comparing their solubilities under equilibrium conditions to the measured, calculated or estimated activities of their component species: $\mathrm{Zn}^{2+}, \mathrm{Al}^{3+}, \mathrm{Ca}^{2+}, \mathrm{OH}^{-}, \mathrm{HPO}_{4}{ }^{2-}, \mathrm{HCO}_{3}{ }^{-}$and $\mathrm{Si}(\mathrm{OH})_{4}$. Calculations were performed using the Phreeqc code (Parkhurst and Appelo, 1999) using the Lawrence Livermore National Laboratory (LLNL) thermodynamic database (Wolery, 1992), except for $\mathrm{Zn}$ and Al hydrolysis constants (Baes and Mesmer, 1976), constants of aqueous $\mathrm{Zn}$-carbonate species (Fouillac and Criaud, 1984), and other solubility constants listed in Table 2. A $0.05 \mathrm{M}$ 
ionic strength was used for the calculation of activity coefficients. This value was estimated from the experimental average $[\mathrm{Ca}]_{\mathrm{aq}}$ value $\left(\sim 10 \mathrm{mmol} \mathrm{L}^{-1}\right)$ (Fig. 16b). The aqueous concentrations of $\mathrm{Zn}, \mathrm{Al}, \mathrm{OH}^{-}$, and $\mathrm{PO}_{4}{ }^{3-}$ in the pore solutions of experiment pots were measured every three weeks. Measured $[\mathrm{Al}]_{\text {aq }}$ was always below the $3 \mu \mathrm{mol} \mathrm{L}{ }^{-1}$ detection limit, thus we considered that a lower limit for the $\left(\mathrm{Al}^{3+}\right)$ activity was determined by the solubility product of gibbsite $\left(\alpha-\mathrm{Al}(\mathrm{OH})_{3(\mathrm{~s})}\right)$. The total concentration of inorganic carbonate was estimated from the open reactor conditions: soil $\mathrm{pCO}_{2}$ is at minimum equal to the atmospheric $\mathrm{pCO}_{2}\left(10^{-3.5} \mathrm{~atm}\right.$.), and may reach $10^{-1.5}$ atm. under extreme conditions (Reardon et al., 1979; Brook et al., 1983). Rapid gas exchange, and thus non-extreme conditions, probably occurred in the seeded pots since relatively rapid desiccation and crack formation were observed. Therefore, we considered that the $\mathrm{pCO}_{2}$ partial pressure of $10^{-2.5}$ atm. was a reasonable upper bound limit. Finally, in most terrestrial waters, the $\left[\mathrm{Si}(\mathrm{OH})_{4}\right]_{\mathrm{aq}}$ value is bounded by the solubility of well crystallized and amorphous $\mathrm{SiO}_{2}$ polymorphs and, consistently, a high and low concentration limit of 0.1 and $1 \mathrm{mmol} \mathrm{L}^{-1}$ were considered in the simulations (Davies and Dewiest, 1966; Rimstidt and Barnes, 1980; Rimstidt, 1997).

The analyzed solution compositions from the pot experiments were plotted in $[\mathrm{Zn}]_{\mathrm{aq}}$ $\mathrm{pH}$ equilibrium diagrams for the various solid phases. Calculated saturation concentrations of $[\mathrm{Zn}]_{\mathrm{aq}}$ for $\mathrm{Zn}$ hydroxide and hydrotalcite exceed all experimental [Zn $]_{\mathrm{aq}}$ values (Fig. 16a). Consequently, these solids are not expected to form under chemical equilibrium conditions in homogneous systems. Hydrozincite $\left(\mathrm{Zn}_{5}(\mathrm{OH})_{6}\left(\mathrm{CO}_{3}\right)_{2}\right)$, smithsonite $\left(\mathrm{ZnCO}_{3}\right)$, and $\mathrm{ZnCO}_{3}: \mathrm{H}_{2} \mathrm{O}$ may have formed in some samples assuming high $\mathrm{pCO}_{2}\left(10^{-2.5} \mathrm{~atm}\right.$.) conditions. At lower $\mathrm{pCO}_{2}$, their formation is less likely. Hydrozincite and zinc carbonates, which may have controlled Zn solubility in a few samples, were not detected by EXAFS spectroscopy. Conversely, hydrotalcite could not form in any samples at thermodynamic equilibrium, and this inference remained valid even when congruent dissolution of hydrotalcite was assumed, i.e. for conditions where the formation of gibbsite and the consequent depletion of dissolved Al(III) 
was omitted from the calculation (data not shown), or when $\mathrm{pCO}_{2}$ was raised one order of magnitude and gibbsite precipitation allowed.

Experimental $\left[\mathrm{PO}_{4}\right]_{\text {aq }}$ values range between about $10^{-5.5}$ and $10^{-4.5} \mathrm{~mol} \mathrm{~L}^{-1}$ (Fig. 16b). The equilibrium $[\mathrm{Zn}]_{\mathrm{aq}}$ curves for hopeite and scholzite calculated for the two extreme experimental $\left[\mathrm{PO}_{4}\right]_{\text {aq }}$ values go through a number of experimental $[\mathrm{Zn}]_{\mathrm{aq}}$ values, indicating that pot solutions were either slightly under- or over-saturated relative to these Zn-phosphate phases. In this calculation, the number of oversaturated $[\mathrm{Zn}]_{\text {aq }}$ points are probably overestimated because the total dissolved phosphorus was considered to be equal to all reactive orthophosphate. A correction of this effect would result in an upward shift of the $[\mathrm{Zn}]_{\mathrm{aq}}$ curve, just as the occurrence of organically-bound $\mathrm{Zn}$. Thus, our data suggest that most solutions were undersaturated with respect to well crystalline $\mathrm{Zn}$ phosphate solids. Of course, these equilibrium thermodynamic calculations are consistent with $\mathrm{Zn}$ surface sorption and $\mathrm{Zn} / \mathrm{Ca}$ surface exchange on phosphate minerals, as in the $\mathrm{ZnPhos}$ surrogate.

The solubility of Zn-kerolite was estimated by Manceau et al. (2000). The calculated Zn solubility of this phase is lower than that of the other solids, and theoretical equilibrium and experimental $[\mathrm{Zn}]_{\mathrm{aq}}$ values fall in the same range of concentration. Since the accuracy of the solubility product for this phase is relatively low, the saturation concentration of $\mathrm{Zn}$ was calculated by increasing the constant by six logarithmic units (i.e., $\mathrm{K}_{\mathrm{ZnKer}}=14$ instead of 8), and assuming that $\left[\mathrm{Si}(\mathrm{OH})_{4}\right]$ was bounded by the solubility of quartz $\left(\mathrm{Si}_{\text {low }}=0.1 \mathrm{mmol} \mathrm{L}^{-1}\right)$ or amorphous silica $\left(\mathrm{Si}_{\text {high }}=1 \mathrm{mmol} \mathrm{L}{ }^{-1}\right)$. Pot solutions are oversaturated when $\mathrm{K}_{\mathrm{ZnKer}}=8$ and $\left[\mathrm{Si}(\mathrm{OH})_{4}\right]$ is controlled by the dissolution of amorphous silica (Fig. 16c). Decreasing the solubility constant to the lower bound limit led to strong oversaturation of $\mathrm{Zn}$ with respect to Zn-kerolite (not shown). The solution became progressively undersaturated when the solubility constant was increased to 14 and the amount of dissolved silica was set at equilibrium with amorphous silica. In these calculations, the soil kerolite was assumed to be purely dioctahedral and devoid of $\mathrm{Mg}$ and $\mathrm{Al}$. However, we know from EXAFS spectroscopy that the neoformed 
kerolite-like mineral contains $\mathrm{Mg}$ (and possibly Al) and, hence, has a different solubility product from the pure $\mathrm{Zn}$ kerolite considered here. The solubility product of $\mathrm{Zn}-\mathrm{Mg}$ kerolites is unknown, but it is certainly lower than that of the pure end-member (i.e., ZnKer 300), otherwise the synthesis of mixed $\mathrm{Zn}-(\mathrm{Mg}, \mathrm{Al})$ solids would not be possible ( $\mathrm{Zn}$ would not have mixed with $\mathrm{Mg} / \mathrm{Al}$ at the atomic scale). This calculation shows that the solubility limit of the Zn-rich (Zn,Mg)-kerolite phase identified by EXAFS spectroscopy (ZnKer210) was reached at least temporarily and in all pots. Therefore, we conclude that this phase is thermodynamically stable under the experimental conditions.

In summary, equilibrium thermodynamic calculations showed that the chemical compositions of pot solutions are consistent with the formation of high $\mathrm{Zn}$ trioctahedral phyllosilicate and to some extent with phosphate, but not with the precipitation of ( $\mathrm{Zn}, \mathrm{Al})$ hydrotalcite. In the conditions of our experiments, hydrotalcite $\left(\mathrm{Zn}_{2} \mathrm{Al}(\mathrm{OH})_{6} \cdot\left(\mathrm{CO}_{3}\right)_{0.5}\right)$ is thermodynamically unstable with respect to hydrozincite $\left(\mathrm{Zn}_{5}(\mathrm{OH})_{6} \cdot\left(\mathrm{CO}_{3}\right)_{2}\right)$ and smithsonite $\left(\mathrm{ZnCO}_{3}\right)$ and, consequently, this solid should not form in our sediment nor, by extrapolation, in the surficial environment at near-neutral $\mathrm{pH}$. However, its presence in slightly alkaline and acidic natural matrices has been established here by $\mu$-EXAFS and was suggested previously by chemical treatment and bulk EXAFS analysis (Voegelin et al., 2002; Juillot et al., 2003). Therefore, hydrotalcite formation ought to result from heterogeneous precipitation since precipitate nuclei have a lower interfacial energy on a sorbent surface than in solution. For example, Trainor et al. (2000) observed the formation of ( $\mathrm{Zn}, \mathrm{Al})$-hydrotalcite upon $\mathrm{Zn}$ sorption on alumina in conditions of undersaturation with respect to the homogeneous precipitation of Zn solids, and similar results were obtained with nickel and cobalt on the same or other Alcontaining substrates (Espinose De La Caillerie et al., 1995; Scheidegger et al., 1997; Scheckel et al., 2000; Elzinga and Sparks, 2001). This phenomenon can be rationalized by considering that the activity of $\mathrm{Al}$ is higher in the immediate vicinity of an aluminous solid and, consequently, that the metal activity required for the formation of hydrotalcite is lower. Figure 
16a shows that gibbsite, whose solubility is several orders lower than hydrotalcite at $\mathrm{pH}<8$, may act as a nucleation substrate for the heterogeneous nucleation and precipitation of hydrotalcite. Another possible aluminous substrate is $\mathrm{Al}$ octahedral interlayer sheets in smectite and vermiculite clays (Chen et al., 2001; Marques et al., 2002; Scheinost et al., 2002; Manceau et al., 2004).

\section{CONCLUDING REMARKS}

After two years of phytostabilization, zinc sulfide, which is unstable under atmospheric conditions, was almost completely dissolved in the presence of plants, and $\mathrm{Zn}$ was immobilized as phosphate and, to a lesser extent, as Zn-phyllosilicate and/or (Zn,Al)-hydrotalcite. During this period, less than $0.2 \%$ of the total amount of $\mathrm{Zn}$ was exported in percolating waters collected under the pots (Bert et al., 2003) owing to the low solubility of the neoformed Zncontaining phases. Although P-containing mineral amendments were not necessary to form $\mathrm{Zn}$ phosphate, increasing artificially the amount of soluble phosphorous is recommended to prevent its deficiency in plants if the $\mathrm{Zn}$ to $\mathrm{P}$ ratio in the treated soil or sediment is high. Adding phosphorous amendments may also help to reduce the sediment phytotoxicity, especially at the beginning of its vegetation when the most mobile fraction of $\mathrm{Zn}$ can be transferred easily to plants. One should bear in mind, however, that the solubility of phosphorous from a given amendment depends on the $\mathrm{pH}$ of the treated matrix, and that the richest $\mathrm{P}$ amendment is not necessarily the most efficient one.

This work illustrates the usefulness of combining electron microscopy and state-of-theart X-ray synchrotron-based techniques and data analysis to scrutinize and quantify the chemical forms of metals in heterogeneous and complex natural matrix. Application of these techniques allowed us to detect the formation of $\mathrm{Zn}$-phosphate, to show that its formation was catalyzed by plants, and specifically by the rhizosphere activity, and to quantify the 
mineralogical transformations caused by the treatment process (i.e., phytostabilization). However, the rhizosphere is a complex multi-parameter biogeochemical system, and the key mechanisms responsible for the enhanced $\mathrm{ZnS}$ dissolution and formation of secondary $\mathrm{Zn}$ precipitates and mineral surface sorption complexes remain unclear. In future studies, laterally resolved X-ray techniques, such as $\mu$-SXRF, $\mu$-EXAFS and $\mu$-XRD, will be particularly helpful to shed light on these questions.

Acknowledgment - B. Girondelot and F. Marseille are thanked for the set up of pot experiments, and water collection and analyses. Frederic Goldschmidt is acknowledged for his assistance during the MEB analyses, O. Proux, J.L. Hazemann, J.J. Menthonnex, and B. Lanson for their assistance during EXAFS measurements, M. Lanson for her help in the preparation of sample references, and P. Hinsinger for insightful discussions. Experiment design benefited from discussions in the European PHYTODEC program. The CNRS, which supports the French-CRG program at ESRF, and the ALS, are acknowledged for the provision of beamtime. The research at the ALS was supported by the Director, Office of Energy Research, Office of Basic Energy Sciences, Materials Sciences Division of the U.S. Department of Energy, under Contract No. DE-AC03-76SF00098. 


\section{REFERENCES}

Asady G. H. and Smucker A. J. M. (1989) Compaction and root modifications of soil aeration. Soil Sci. Soc. Am. J. 53, 251-254.

Baes C.F. and Mesmer R.E. (1976) The hydrolysis of cations. John Wiley \& Sons, New York.

Baize D. (2000) Teneurs en "métaux lourds" dans les sols français. Courrier de l'environnement de l'INRA 22(39), 39-54.

Banfield J. F., Barker W. W., Welch S. A., and Taunton A. (1999) Biological impact on mineral dissolution : application of the lichen model to understanding mineral weathering in the rhizosphere. Proc. Natl. Acad. Sci. U.S.A. 96, 3404-3411.

Barker W. W., Welch S. A., Chu S., and Banfield J. F. (1998) Experimental observations of the effects of bacteria on aluminosilicate weathering. Am. Mineral. 83, 1551-1563.

Berner R. A. (1981) A new classification of sedimentary environment. J. Sed. Petrol. 51, 359365.

Berner R. A. (1995) Chemical weathering and its effect on atmospheric $\mathrm{CO}_{2}$ and climate. In Chemical weathering rates of silicate minerals, Vol. 31 (eds. A. F. White and S. L. Brantley), pp. 565-583. Reviews in Mineralogy and Geochemistry, Mineralogical Society of America, Washington.

Bert V., Girondelot B., Marseille F., and Laboudigue A. (2003) Use of vegetation and amendment for re-vegetation and stabilisation of a metal-polluted dredged sediment deposit. Mesocosm experiments and field trial. Proc. $7^{\text {th }}$ Intern. Conf. on the Biogeochem. of Trace Elements, Uppsala (Sweden), 108-109.

Berti W. R. and Cunningham S. D. (2000) Phytostabilization of metals. In Phytoremediation of towic metals: using plants to cleaning up the environment (eds. I. Raskin and B. D. Ensley), pp. 71-88. John Wiley \& Sons, inc., New York. 
Bertrand I., Hinsinger P., Jaillard B., and Arvieu J. C. (1999) Dynamics of phosphorus in the rhizosphere of maize and rape grown on synthetic, phosphated calcite and goethite. Plant and Soil 211, 111-119.

Boisson-Gruppen J. (1999) Réhabilitation des sols pollués en éléments traces par des amendements minéraux. Faisabilité et durabilité d'après la mobilité des éléments et la phytotoxicité du sol. Ph.D. thesis, Institut National Polytechnique de Lorraine, France.

Bormann B. T., Wang D., Bormann F. H., Benoit G., April R., and Snyder M. C. (1998) Rapid, plant-induced weathering in an aggrading experimental ecosystem. Biogeochem. 43, 129-155.

Brook G. A., Folkoff M. E., and Box E. O. (1983) A world model of soil carbon dioxide. Earth Surf. Proc. 8, 79-88.

Calmano W., Mangold S., and Welter E. (2001) An XAFS investigation of the artefacts caused by sequential extraction analyses of Pb-contaminated soils. Fres. J. Anal. Chem. 371, 823-830.

Carroll S. A., O'Day P. A., and Piechowki M. (1998) Rock-water interactions controlling zinc, cadmium, and lead concentrations in surface waters and sediments, U. S. tri-ste minig district. 2. Geochemical interpretation. Environ. Sci. Technol. 32, 956-965.

Cauwenberg P. and Maes A. (1997) Influence of oxidation on sequential chemical extraction of dredged river sludge. Inter. J. Environ. Anal. Chem. 68, 47-57.

Cauwenberg P., Verdonckt F., and Maes A. (1998) Flotation as a remediation technique for heavily polluted dredged material. 1. A feasibility study. Sci. Total Environ. 209, 113119.

Chaignon V., Di Malta D., Hinsinger P. (2002) Fe-deficiency increases Cu acquisition by wheat cropped in a Cu-contaminated vineyard. New Phytol., 154, 121-130.

Chen Z.S., Tsou T.C., Asio V.B., and Tsai C.C. (2001) Genesis of inceptisols on a volcanic landscape in Taiwan. Soil Sci. 166, 255-266. 
Chlopecka A. and Adriano D. (1996) Mimicked in-situ stabilization of metals in a cropped soil: bioavailability and chemical form of zinc. Environ. Sci. Technol. 30, 3294-3303.

Cotter-Howells J. and Caporn S. (1996) Remediation of contaminated land by formation of heavy metal phosphates. Appl. Geochem. 11, 335-342.

Cotter-Howells J., Champness P. E., and Charnock J. M. (1999) Mineralogy of Pb-P grains in the roots of Agrostis capillaris L. by ATEM and EXAFS. Mineral. Mag. 63, 777-789.

Courchesne F. and Gobran G. R. (1997) Mineralogical variations of bulk and rhizosphere soils from a Norway sprice stand. Soil Sci. Soc. Am. J. 61, 1245-1249.

Cunningham S. D., Berti W. R., and Huang J. W. (1995) Phytoremediation of contaminated soils. Trends in Biotechnol. 13, 393-397.

Davies S. N. and DeWiest R. C. M. (1966) Hydrogeology. John Wiley \& Sons, New York.

Davis A. and Atkins D. (2001) Metal distribution in Clark Fork river sediments. Environ. Sci. Technol. 35, 3501-3506.

De Rooij N. M. and Gerrits H. J. (1995) The transport of polluants from a sludge disposal site. Europ. Wat. Pollut. Control 5(5), 43-55.

Dimitrova S. V. and Mehanjiev D. R. (2000) Interaction of blast-furnace slag with heavy metal ions in water solutions. Wat. Res. 34, 1957-1961.

Egli M., Mirabella A., Sartori G., and Fitze P. (2003) Weathering rates as function of climate: results from a climosequence of the Val Geneva (Trentino, italian Alps). Geoderma 111, 99-121.

Elzinga E. J. and Sparks D. L. (2001) Reaction condition effects on nickel sorption mechanisms in illite-water suspensions. Soil Sci. Soc. Am. J. 65, 94-101.

Espinose de la Caillerie J. B. D., Kermarec M., and Clause O. (1995) Impregnation of gammaalumina with $\mathrm{Ni}(\mathrm{II})$ or $\mathrm{Co}(\mathrm{II})$ ions at neutral $\mathrm{pH}$ : Hydrotalcite-type coprecipitate formation and characterization. J. Am. Chem. Soc. 117, 11471-11481. 
Eusden J. D., Gallagher L., Eighmy T. T., Crannell B. S., Krzanowski J. R., Butler L. G., Cartledge F. K., Emery E. F., Shaw E. L., and Francis C. A. (2002) Petrographic and spectroscopic characterization of phosphate-stabilized mine tailings from Leadville, Colorado. Waste Manag. 22, 117-135.

Fajtl J., Kabrna M., Tichy R., and Ledvina R. (2002) Environmental risks associated with aeration of a freshwater sediment exposed to mine drainage water. Env. Geology 41, 563-570.

Fouillac C. and Criaud A. (1984) Carbonate and bicarbonate trace metal complexes: Critical reevaluation of stability constants. Geochemi. J. 18, 297-303.

Francis A. J., Dodge C., Rose A. W., and Ramirez A. J. (1989) Aerobic and anaerobic microbial dissolution of toxic metals from coal wastes: Mecanism of action. Environ. Sci. Technol. 23, 435-441.

Fuierer T. A., Lore M., Puckett S. A., and Nancollas G. H. (1994) A mineralization adsorption and mobility study of hydroxyapatite surfaces in the presence of zinc and magnesium ions. Langmuir 10, 4721-4725.

Greman H., Persolja J., Lobnik F., and Lestan D. (2001) Modifying lead, zinc and cadmium bioavailability in soil by apatite and EDTA addition. Fres. Environ. Bul. 10, 727-730.

Hamon R. E., McLaughling M. J., and Cozens G. (2002) Mechanisms of attenuation of metal availability in In situ remediation treatments. Environ. Sci. Technol. 36, 3991-3996.

Hazemann J. L., Nayouf K., and Debergevin F. (1995) Modelization by finite-elements of sagittal focusing. Nucl. Instr. Meth. Phys. Res. B97, 547-550.

Hinsinger P., Jaillard B. D., and Dufey J. E. (1992) Rapid weathering of a trioctahedral mica by roots of ryegrass. Soil Sci. Soc. Am. J. 56, 977-982.

Hinsinger P. (1998) How do plant roots acquire mineral nutriments? Chemical processes involved in the rhizosphere. Adv. Agron. 64, 225-265. 
Hinsinger P., Barros O., Benedetti M., Noack-Y, and Callot-G. (2001) Plant-induced weathering of a basaltic rock: Experimental evidence. Geochim. Cosmochim. Acta 65, 137-152.

Hinsinger P., Plassard C., Tang C., and Jaillard B. (2003) Origins of root-mediated pH changes in the rhizosphere and their responses to environmental constraints : a review. Plant and Soil 248, 43-59.

Isaure M. P., Laboudigue A., Manceau A., Sarret G., Tiffreau C., Trocellier P., Lamble G., Hazemann J. L., and Chateigner D. (2002) Quantitative Zn speciation in a contaminated dredged sediment by $\mu$-PIXE, $\mu$-SXRF, EXAFS spectroscopy and principal component analysis. Geochim. Cosmochim. Acta 66, 1549-1567.

Isaure M.P., Manceau A., Geoffroy N., Laboudigue A., Tamura N., Marcus M.A. (2005) Zinc mobility and speciation in soil covered by contaminated dredged sediment using micrometer-scale and bulk-averaging X-ray fluorescence, absorption and diffraction techniques. Geochim. Cosmochim. Acta, In press.

Johnson C. A. and Glasser F. P. (2003) Hydrotalcite-like minerals $\left(\mathrm{M}_{2} \mathrm{Al}(\mathrm{OH})_{6}\left(\mathrm{CO}_{3}\right)_{0.5} \times \mathrm{xH}_{2} \mathrm{O}\right.$, where $\mathrm{M}=\mathrm{Mg}, \mathrm{Zn}, \mathrm{Co}, \mathrm{Ni}$ ) in the environment: Synthesis, characterization and thermodynamic stability. Clays Clay Miner. 51, 1-8.

Juillot F., Morin G., Ildefonse P., Trainor T., Benedetti M., Galoisy L., Calas G., and Brown G. (2003) Occurrence of $\mathrm{Zn} / \mathrm{Al}$ hydrotalcite in smelter-impacted soils from northern France: Evidence from EXAFS spectroscopy and chemical extractions. Am. Mineral. 88, 509-526.

Kersten M. and Förstner U. (1986) Chemical fractionation of heavy metals in anoxic estuarine and costal sediments. Wat. Sci. Tech. 18, 121-130.

Kirpichtchikova T., Manceau A., Lanson B., Sarret G., Marcus M. A., and Jacquet T. (2003) Speciation and mobility of heavy metals $(\mathrm{Zn}, \mathrm{Cu}, \mathrm{Pb})$ in soil contaminated by sewage irrigation. J. Phys. 107, 695-698. 
Knox A. S., Seaman J. C., Mench M. J., and Vangronsveld J. (2001) Remediation of metal and radionuclides contaminated soils by in situ stabilization techniques. In Environmental restoration of metals-contaminated (eds. I. K. Iskandar), pp. 21-60. CRC Press LLC.

Kodama H., Nelson S., Yang A. F., and Kohyama N. (1994) Mineralogy of rhizospheric and non-rhizospheric soils in corn fields. Clays Clay Miner. 42, 755-763.

Laperche V., Traina S. J., Gaddam P., and Logan T. J. (1996) Chemical and mineralogical characterization of $\mathrm{Pb}$ in a contaminated soil: Reactions with synthetic apatite. Environ. Sci. Technol. 30, 3321-3326.

Laperche V., Logan T. J., Gaddam P., and Traina S. J. (1997) Effect of apatite amendments on plant uptake of lead from contaminated soil. Environ. Sci. Technol. 31, 2745-2753.

Li Y. M. and Chaney R. L. (1998) Case studies in the field-industrial sites : phytostabilization of zinc-smelter contaminated sites : the Palmerton case. In Metal-contaminated soils : in situ inactivation and phytoremediation (eds. J. Vangronsveld and S. D. Cunningham), pp. 211-216. Springer Verlag, Berlin.

Lindsay W. L., Vlek P. L. G., and Chien S. H. (1989) Phosphate minerals. In Minerals in soil environment (eds. J. B. Dixon and S. B. Weed), pp. 1089-1130. Soil Sci. Soc. Am., Madison.

Lors C., Tiffreau C., and Laboudigue A. (2004) Effects of bacterial activities on the release of heavy metals from contaminated dredged sediments. Submitted.

Lower S. K., Maurice P. A., and Traina S. J. (1998) Simultaneous dissolution of hydroxylapatite and precipitation of hydroxypyromorphite : Direct evidence of homogeneous nucleation. Geochim. Cosmochim. Acta 62, 1773-1780.

Lusvardi G., Menabue L., and Saladini M. (2002) Reactivity of biological and synthetic hydroxylapatite towards $\mathrm{Zn}(\mathrm{II})$ ion, solid-liquid investigations. J. of Materials Sci : Materials in Medicine 13, 91-98. 
Ma Q. Y., Traina S. J., Logan T. J., and Ryan J. A. (1993) In situ lead immobilization by apatite. Environ. Sci. Technol. 27, 1803-1810.

Maes A., Vanthuyne M., Cauwenberg P., and Engels B. (2003) Metal partitioning in a sulfidic canal sediment: metal solubility as a function of $\mathrm{pH}$ combined with EDTA extraction in anoxic conditions. Sci. Total Environ. 312, 181-193.

Manceau A., Chateigner D., and Gates W. P. (1998) Polarized EXAFS, distance-valence leastsquares modeling (DVLS), and quantitative texture analysis approaches to the structural refinement of Garfield nontronite. Phys. Chem. Miner. 25, 347-365.

Manceau A., Schlegel M. L., Nagy K. L., and Charlet L. (1999) Evidence for the formation of trioctahedral clay upon sorption of $\mathrm{Co}^{2+}$ on quartz. J. Coll. Interf. Sci. 220, 181-197.

Manceau A., Lanson B., Schlegel M. L., Hargé J. C., Musso M., Eybert-Bérard L., Hazemann J. L., Chateigner D., and Lamble G. M. (2000) Quantitative Zn speciation in smeltercontaminated soils by EXAFS spectroscopy. Am. J. Sci. 300, 289-343.

Manceau A., Marcus M. A., and Tamura N. (2002a) Quantitative speciation of heavy metals in soils and sediments by synchrotron X-ray techniques. In Applications of Synchrotron Radiation in Low-Temperature Geochemistry and Environmental Science, Vol. 49 (eds. P. Fenter, M. Rivers, N. Sturchio, and S. Sutton), pp. 341-428. Reviews in Mineralogy and Geochemistry, Mineralogical Society of America, Washington.

Manceau A., Tamura N., Marcus M., MacDowell A., Celestre R., Sublett R., Sposito G., and Padmore H. (2002b) Deciphering Ni sequestration in soil ferromanganese nodules by combining X-ray fluorescence, absorption, and diffraction at micrometer scales of resolution. Am. Mineral. 87, 1494-1499.

Manceau A., Tamura N., Celestre R., MacDowell A., Geoffroy N., Sposito G., and Padmore H. (2003) Molecular-scale speciation of $\mathrm{Zn}$ and $\mathrm{Ni}$ in soil ferromanganese nodules from loess soils of the Mississippi Basin. Environ. Sci. Technol. 37, 75-80. 
Manceau A., Marcus M., Tamura N., Proux O., Geoffroy N., and Lanson B. (2004) Natural speciation of $\mathrm{Zn}$ at the micrometer scale in a clayey soil using X-ray fluorescence, absorption, and diffraction. Geochim. Cosmochim. Acta, 68, 2467-2483.

Marcus M., MacDowell A.A., Celestre R., Manceau A., Miller T., Padmore H.A., Sublett R.E. (2004) Beamline 10.3.2 at ALS: a hard X-ray microprobe for environmental and materials sciences. J. Synch. Rad. 11, 239-247.

Marques J.J., Teixeira W.G., Schulze D.G., and Curi N. (2002) Mineralogy of soils with unusually high exchangeable Al from the western Amazon Region. Clay Min. 37, 651661.

Marschner H. (1991) Root-induced changes in the availability of micronutriments in the rhizosphere. In Plants roots. The hidden half (eds. Y. Waisel, A. Eshel, and U. Kafkafi), pp. 503-528, New York.

Marschner H. (1995) Mineral Nutrition of Higher Plants. Second edition. Academic press, London.

Marseille F., Tiffreau C., Laboudigue A., and Lecomte P. (2000) Impact of vegetation on the mobility and bioavailability of trace elements in a dredged sediment deposit; a greenhouse study. Agronomie 20, 547-556.

Martin P. (1991) Evolution et distribution de la fertilité phosphorique dans les agrosystèmes prairiaux : conséquences en matière de diagnostique. Ph.D. thesis, I.N.P.L, Nancy (France).

Mench M., Didier V. L., Loffler M., Gomez A., and Masson P. (1994a) A mimicked in situ remediation study of metal-contaminated soils with emphasis on cadmium and lead. $J$. Environ. Qual. 23, 58-63.

Mench M., Vangronsveld J., Didier V., and Clijsters H. (1994b) Evaluation of metal mobility, plant availability and immobilisation by chemical agents in a limed-silty soil. Environ. pollution 86, 279-286. 
Mench M. J., Manceau A., Vangronsveld J., Clijsters H., and Mocquot B. (2000) Capacity of soil amendments in lowering the phytoavailability of sludge-borne zinc. Agronomie 20, 383-397.

Mench M., Bussière S., Boisson-Gruppen J., Castaing E., Vangronsveld J., Ruttens A., De Koe T., Bleeker P., Assunção A., and Manceau A. (2003a) Progress in remediation and revegetation of the barren Jales gold mine spoil after in situ treatments. Plant and Soil 249, 187-202.

Mench M., Vangronsveld J., Lepp N. W., Ruttens A., Bleeker P., and Geebelen W. (2003b) Soil amendments for attenuating trace element exposure. In Natural attenuation of trace element availability in soils. (eds. R. Hamon and M. McLaughling), pp. in press.

Misra D. N. and Bowen R. L. (1981) Interaction of zinc ions with hydroxylapatite. In Adsorption from aqueous solutions (eds. P. H. Tewari), pp. 179-192.

Motelica H. M., Naylor C., Zhang H., and Davison W. (2003) Simultaneous release of metals and sulfide in lacustrine sediment. Environ. Sci. Technol. 37, 4374-4381.

Neuhausler U., Feng H., and Jones K. W. (2003) Characterization of sulfur in New York New Jersey waterway sediment. J. Phys. IV 104, 439-442.

Neumann G., Massonneau A., Martinoia E., and Römheld V. (1999) Physiological adaptations to phosphorus deficiency during proteoid root development in white lupin. Planta 208, 373-382.

Nordborg F. and Olsson S. (1999) Changes in soil mineralogy and exchangeable cation pools in stands of norway spruce planted on former pasture land. Plant and Soil 207, 219-229.

Nriagu J. O. (1984) Formation and stability of base metal phosphates in soils and sediments. In Phosphate Minerals (eds. J. O. Nriagu and P. B. Moore), pp. 318-329,. Springer Verlag, New York.

O'Day P., Carrol S. A., and Waychunas G. A. (1998) Rock-Water interactions controlling zinc, cadmium, and lead concentrations in surface waters and sediments, US tri-state mining 
district. 1. Molecular identification using X-ray absorption spectroscopy. Environ. Sci. Technol. 32, 943-955.

O'Day P., Caroll S. A., Randall S., Martinelli R. E., Anderson S. L., Jelinski J., and Knezovich J. P. (2000) Metal speciation and bioavailability in contaminated estuary sediments, Alameda naval air station, California. Environ. Sci. Technol. 34, 3665-3673.

Osan J., Kurunczi S., Torok S., and Van Grieken R. (2002) X-Ray analysis of riverbank sediment of the Tisza (Hungary): identification of particles from a mine pollution event. Spectrochim. Acta Part B Atomic Spec. 57, 413-422.

Ostergren J. D., Brown G. E., Parks G. A., and Tingle T. N. (1999) Quantitative speciation of lead in selected tailings from Leadville, Co. Environ. Sci. technol. 33, 1627-1636.

Parkhurst, D.L. and Appelo, C.A.J. (1999) User's guide to PHREEQC (Version 2). A computer program for speciation, batch-reaction, one-dimensional transport, and inverse geochemical calculations. U.S. Geological Survey Water-Resources Investigations Report 99-4259, 310 p.

Peaudecerf A. (2002) Influence de cations sorbés sur la dissolution de l'apatite - approches microscopique et macroscopique. Ph.D. thesis, University of J. Fourier, France.

Preis W. and Gamsjäger H. (2001) (Solid + solute) phase equilibria in aqueous solution. XIII. Thermodynamic properties of hydrozincite and predominance diagrams for $\left(\mathrm{Zn}^{2+}+\right.$ $\mathrm{H}_{2} \mathrm{O}+\mathrm{CO}_{2}$ ). J. Chem. Therm. 33, 803-819.

Qureshi S., Richards B. K., Hay A. G., Tsai C. C., Mc Bride M. B., Baveye P., and Steenhuis T. S. (2003) Effect of microbial activity on trace element release from sewage sludge. Environ. Sci. Technol. 37, 3361-3366.

Reardon E. J., Allison G. B., and Fritz P. (1979) Seasonal chemical and isotopic variations of soil $\mathrm{CO}_{2}$ at Trout Creek, Ontario. J. Hydrol. 43, 355-371.

Ressler T., Wong J., Roos J., and Smith I. L. (2000) Quantitative speciation of Mn-bearing particulates emitted from autos burning (methylcyclopentadienyl) manganese 
tricarbonyl-added gasolines using XANES spectroscopy. Environ. Sci. Technol. 34, 950-958.

Rimstidt J. D. and Barnes H. L. (1980) The kinetics of silica-water reactions. Geochim. Cosmochim. Acta 44, 1683-1699.

Rimstidt J. D. (1997) Quartz solubility at low temperatures. Geochim. Cosmochim. Acta 61, $2553-2558$

Roberts D., Scheinost A., and Sparks D. (2002) Zinc speciation in a smelter-contaminated soil profile using bulk and microspectroscopic techniques. Environ. Sci. Technol. 36, 17421750.

Römheld V. and Marschner H. (1990) Genotypical differences among graminaceous species in release of phytosiderophores and uptake of iron phytosiderophores. Plant and Soil 123, $147-153$

Ryan J. A., Zhang P., Hesterberg D., Chou J., and Sayers D. E. (2001) Formation of chloropyromorphite in a lead-contaminated soil amended with hydroxylapatite. Environ. Sci. Technol. 35, 3798-3803.

Sappin-Didier V. (1995) Utilisation de composés inorganiques pour diminuer les flux de métaux dans deux agrosystèmes pollués : étude des mécanismes impliqués par l'emploi d'un composé du fer. Ph.D. thesis, University of Bordeaux I, France.

Sarret G. (1998) Biogéochime structurale du zinc et du plomb par spectroscopie EXAFS: Interactions avec des acides humiques, des parois cellulaires de champignon et des lichens. Ph.D. thesis, University J. Fourier, Grenoble, France.

Sarret G., Schroeder W. H., Marcus M. A., Geoffroy N., and Manceau A. (2003) Localization and speciation of $\mathrm{Zn}$ in mycorrhized roots by $\mu \mathrm{SXRF}$ and $\mu$ EXAFS. J. Phys. IV 107, 1193-1196.

Sarret G., Balesdent J., Bouziri L., Garnier J. M., Marcus M. A., Geoffroy N., Panfili F., and Manceau A. (2004) Zn speciation in the organic horizon of a contaminated soil by 
micro X-ray fluorescence, micro and powder EXAFS spectroscopy and isotopic dilution. Environ. Sci. Technol., in press.

Scheckel K. G., Scheinost A. C., Ford R. G., and Sparks D. L. (2000) Stability of layered Ni hydroxide surface precipitates - A dissolution kinetics study. Geoch. Cosmoch. Acta. 64, 2727-2735.

Scheidegger A. M., Lamble G. M., and Sparks D. L. (1997) Spectroscopic evidence for the formation of mixed-cation hydroxide phases upon metal sorption on clays and aluminum oxides. J. Coll. Interf. Sci. 186, 118-128.

Scheinost A. C., Kretzschmar R., Pfister S., and Roberts D. R. (2002) Combining selective sequential extractions, $\mathrm{x}$-ray absorption spectroscopy, and principal component analysis for quantitative zinc speciation in soil. Environ. Sci. Technol. 36, 5021-5028.

Schlegel M. L., Manceau A., Charlet L., Chateigner D., and Hazemann J. L. (2001) Sorption of metal ions on clay minerals. III. Nucleation and growth of Zn phyllosilicate on the edges of hectorite. Geochim. Cosmochim. Acta 65, 4155-4170..

Seaman J. C., Arey J. S., and Bertsch P. M. (2001) Immobilization of nickel and other metals in contaminated sediments by hydroxyapatite addition. J. Environ. Qual. 30, 460-469.

Sinaj S., Frossard E., Fardeau J. C., Lhote F., and Morel J. L. (1994) Observation directe de l'altération de scories de déphosphoration après incorporation dans un sol acide cultivé. In C. R. Acad. Sci. Paris, t. 319, série II,, pp. 1207-1214.

Smith R. M. and Martell A. E. (1976) Critical stability constants. Vol. 4. Inorganic complexes. Plenum Press. New York and London.

Spannagel P., Gerardin R., Jeannot F., and Evrard O. (1997) Analyse et caractérisation approfondies d'une scorie d'aciérie issue de fonte hématite. Revue Métallurgique-CIT, Mars 1997, 347-357.

Thiry M. and Van Oort F. (1999) Les phases minérales majeures et mineures d'une friche industrielle de métallurgie des métaux non-ferreux : Etat d'altération, évolution 
géochimique et devenir des métaux polluants du site de Mortagne-du-Nord. In spéciation des métaux dans le sol, pp. 108-135. Publications Ecrin, Paris.

Thiry M., Huet-Taillanter S., and Schmitt J. M. (2002) La friche industrielle de Mortagne-duNord (59) - I - Prospection du site, composition des scories, hydrochimie, hydrologie et estimation des flux. Bull. Soc. Géol. France 173, 369-381.

Trainor P. T., Brown Jr. G. E., and Parks G. A. (2000) Adsorption and precipitation of aqueous Zn(II) on alumina powders. J. Coll. Interf. Sci. 231, 359-372.

Valsami-Jones E., Ragnarsdottirb K. V., Putnisc A., Bosbachc D., Kempb A. J., and Cresseya G. (1998) The dissolution of apatite in the presence of aqueous metal cations at pH 2-7. Chem. Geology 151, 215-233.

Vangronsveld J., Sterckx J., Van Assche F., and Clijsters H. (1995a) Rehabilitation studies on an old non-ferrous waste dumping ground: effects of revegetation and metal immobilization by beringite. J. Geochem. Explor. 52, 221-229.

Vangronsveld J., Van Assche F., and Clijsters H. (1995b) Reclamation of a bare industrial area contaminated by non-ferrous metals: in situ metal immobilization and revegetation. Environ. Pollution 87, 51-59.

Vangronsveld J. (1998) Case studies in the field-industrial sites : phytostabilization of zincsmelter contaminated sites : the Lommel-Maatheid case. In Metal-contaminated soils : in situ inactivation and phytoremediation (eds. J. Vangronsveld and S. D. Cunningham), pp. 211-216. Springer Verlag, Berlin.

Voegelin A., Scheinost A. C., Bühlmann K., Barmettler K., and Kretzschmar R. (2002) Slow formation and dissolution of $\mathrm{Zn}$ precipirtates in soil: A combined column transport and XAFS study. Environ. Sci. Technol. 36, 3749-3754.

Wasserman S. R. (1997) The analysis of mixtures: application of principal component analysis to XAS spectra. J. Phys. IV 7, 203-205. 
Wasserman S. R., Allen P. G., Shuh D. K., Bucher J. J., and Edelstein N. M. (1999) EXAFS and principal component analysis : a new shell game. J. Synchro. Rad. 6, 284-286.

Webb S., Leppard G., and Gaillard J. (2000) Zinc speciation in a contaminated aquatic environment: Characterization of environmental particles by analytical electron microscopy. Environ. Sci. Technol. 34, 1926-1933.

White A. F. (1995) Chemical weathering rates of silicate minerals in soils. In Chemical weathering rates of silicate minerals, Vol. 31 (eds. A. F. White and S. L. Brantley), pp. 407-462. Reviews in Mineralogy and Geochemistry, Mineralogical Society of America, Washington.

Wolery T. (1992) EQ3/6. A software package for geochemical modelling of aqueous systems: package overview and installation guide (version 7.0), Technical Report UCRL- MA110662 PT I ed., Lawrence Livermore National Laboratory, USA

Xu Y. and Schwartz F. W. (1994) Sorption of $\mathrm{Zn}^{2+}$ and $\mathrm{Cd}^{2+}$ on hydroxyapatite surfaces. Environ. Sci. Technol. 28, 1472-1480.

Zhang F., Romheld V., and Marschner H. (1989) Effect of zinc deficiency in wheat on the release of zinc and iron mobilizing root exudates. Z. Pflanzenernähr. Bodenk. 152, 205210.

Zhang P. and Ryan J. A. (1999) Transformation of $\mathrm{Pb}(\mathrm{II})$ from cerrusite to chloropyromorphite in the presence of hydroxylapatite under varying conditions of pH. Environ. Sci. Technol. 33, 625-630.

Zhuang Y., Allen H. E., and Fu G. (1994) Effect of aeration of sediment on cadmium binding. Environ. Tox. Chem. 13, 717-724.

Zhuang F. S., Ma J., and Cao Y. P. (1997) Phosphorus deficiency enhances root exudation of low-molecular weight organic acids and utilization of sparingly soluble inorganic phosphates by radish and rape plants. Plant and Soil 196, 261-264. 
Table 1. Metal composition in weight percent and physico-chemical characteristics of the sediment at the beginning of the experiment.

\begin{tabular}{lcccc}
\hline $\begin{array}{l}\text { Element } \\
\text { Concentration }\end{array}$ & $\mathrm{Zn}$ & $\mathrm{Pb}$ & $\mathrm{Cd}$ & $\mathrm{Cu}$ \\
$\left(\mathrm{mg} \mathrm{kg}^{-1}\right)$ & 4700 & 700 & 123 & 150 \\
\hline Physico-chemical & $\mathrm{pH}$ & TOC (\%) & $\mathrm{IC} \mathrm{( \% )}$ & Humidity (\%) \\
Characteristics & 7.8 & 7.2 & 0.7 & 28
\end{tabular}

TOC : Total organic carbon

IC : Inorganic carbon

Humidity : Water lost at $70^{\circ} \mathrm{C}$ in weight percent. 
Table 2. Solubility products of the various solids used to calculate the saturation concentration diagrams of $\mathrm{Zn}$.

\begin{tabular}{|c|c|c|c|}
\hline Solid & Ion activity product & $\mathrm{K}_{\mathrm{s}}$ & Reference \\
\hline $\begin{array}{l}\text { Gibbsite } \\
\mathrm{Al}(\mathrm{OH})_{3}\end{array}$ & $\left(\mathrm{Al}^{3+}\right)\left(\mathrm{H}^{+}\right)^{-3}$ & 8.5 & $\begin{array}{l}\text { Smith and } \\
\text { Martell (1976) }\end{array}$ \\
\hline $\mathrm{Zn}(\mathrm{OH})_{2(\mathrm{am})}$ & $\left(\mathrm{Zn}^{2+}\right)\left(\mathrm{H}^{+}\right)^{-2}$ & 12.45 & $\begin{array}{l}\text { Smith and } \\
\text { Martell (1976) }\end{array}$ \\
\hline $\begin{array}{l}\text { Hydrozincite } \\
\mathrm{Zn}_{5}(\mathrm{OH})_{6}\left(\mathrm{CO}_{3}\right)_{2}\end{array}$ & $\left(\mathrm{Zn}^{2+}\right)^{5}\left(\mathrm{HCO}_{3}^{-}\right)^{2}\left(\mathrm{H}^{+}\right)^{-8}$ & $29.4 \pm 0.5$ & $\begin{array}{l}\text { Preis and } \\
\text { Gamsjäger } \\
(2001)\end{array}$ \\
\hline $\begin{array}{l}\text { Hydrotalcite } \\
\mathrm{Zn}_{2} \mathrm{Al}(\mathrm{OH})_{6}\left(\mathrm{CO}_{3}\right)_{0.5} \cdot \mathrm{nH}_{2} \mathrm{O}\end{array}$ & $\left(\mathrm{Zn}^{2+}\right)^{2}\left(\mathrm{Al}^{3+}\right)\left(\mathrm{HCO}_{3}^{-}\right)^{0.5}\left(\mathrm{H}^{+}\right)^{-6.5}$ & $26 \pm 1$ & $\begin{array}{l}\text { Johnson and } \\
\text { Glasser (2003) }\end{array}$ \\
\hline $\begin{array}{l}\text { Zn-kerolite } \\
\mathrm{Si}_{4} \mathrm{Zn}_{3} \mathrm{O}_{10}(\mathrm{OH})_{2} \cdot \mathrm{nH}_{2} \mathrm{O}\end{array}$ & $\left(\mathrm{Zn}^{2+}\right)^{3}\left(\mathrm{Si}\left(\mathrm{OH}_{4}\right)\right)^{4}\left(\mathrm{H}^{+}\right)^{-6}$ & $8 \pm 6$ & $\begin{array}{l}\text { Manceau et al. } \\
(2000)\end{array}$ \\
\hline $\begin{array}{l}\text { Smithsonite } \\
\mathrm{ZnCO}_{3}\end{array}$ & $\left(\mathrm{Zn}^{2+}\right)\left(\mathrm{HCO}_{3}\right)\left(\mathrm{H}^{+}\right)^{-1}$ & 0.46 & $\begin{array}{l}\text { V8.R6.230 } \\
\text { database }^{*}\end{array}$ \\
\hline $\mathrm{ZnCO}_{3}: \mathrm{H}_{2} \mathrm{O}$ & $\left(\mathrm{Zn}^{2+}\right)\left(\mathrm{HCO}_{3}\right)\left(\mathrm{H}^{+}\right)^{-1}$ & 0.14 & $\begin{array}{l}\text { V8.R6.230 } \\
\text { database }^{*}\end{array}$ \\
\hline $\begin{array}{l}\text { Hopeite } \\
\mathrm{Zn}_{3}\left(\mathrm{PO}_{4}\right)_{2}: 4 \mathrm{H}_{2} \mathrm{O}\end{array}$ & $\left(\mathrm{Zn}^{2+}\right)^{3}\left(\mathrm{HPO}_{4}{ }^{2-}\right)^{2}\left(\mathrm{H}^{+}\right)^{-2}$ & -10.66 & $\begin{array}{l}\text { V8.R6.230 } \\
\text { database * }\end{array}$ \\
\hline $\begin{array}{l}\text { Scholzite } \\
\mathrm{Zn}_{2} \mathrm{Ca}\left(\mathrm{PO}_{4}\right)_{2}\left(\mathrm{H}_{2} \mathrm{O}\right)_{2}\end{array}$ & $\left(\mathrm{Zn}^{2+}\right)^{2}\left(\mathrm{Ca}^{2+}\right)\left(\mathrm{HPO}_{4}{ }^{2-}\right)^{2}\left(\mathrm{H}^{+}\right)^{-2}$ & -9.46 & Nriagu (1984) \\
\hline $\begin{array}{l}\text { Spencerite } \\
\mathrm{Zn}_{4}\left(\mathrm{PO}_{4}\right)_{2}(\mathrm{OH})_{2}\end{array}$ & $\left(\mathrm{Zn}^{2+}\right)^{4}\left(\mathrm{HPO}_{4}^{2-}\right)^{2}\left(\mathrm{H}^{+}\right)^{-4}$ & -0.166 & Nriagu (1984) \\
\hline $\begin{array}{l}\text { Tarbuttite } \\
\mathrm{Zn}_{2}\left(\mathrm{PO}_{4}\right) \mathrm{OH}\end{array}$ & $\left(\mathrm{Zn}^{2+}\right)^{2}\left(\mathrm{HPO}_{4}^{2-}\right)\left(\mathrm{H}^{+}\right)^{-2}$ & -0.283 & Nriagu (1984) \\
\hline $\begin{array}{l}\text { Hydroxylapatite } \\
\mathrm{Ca}_{5}(\mathrm{OH})(\mathrm{PO} 4)_{3}\end{array}$ & $\left(\mathrm{Ca}^{2+}\right)^{5}\left(\mathrm{HPO}_{4}^{2-}\right)^{3}\left(\mathrm{H}^{+}\right)^{-4}$ & -3.07 & $\begin{array}{l}\text { V8.R6.230 } \\
\text { database }^{*}\end{array}$ \\
\hline
\end{tabular}


Table 3. Sample nomenclature

\begin{tabular}{lccc}
\hline Plant & \multicolumn{3}{c}{ Substrate } \\
\hline & no amendment & $\begin{array}{c}\text { hydroxylapatite } \\
\text { (AP) }\end{array}$ & Thomas basic slag \\
& & SAP & (TS) \\
\hline no plant & S & STS \\
Festuca rubra & SFR & SAPFR & STSFR \\
Agrostis tenuis & SAT & SAPAT & STSAT \\
\hline
\end{tabular}


Table 4. Pseudobinary composition analysis on bulk spectra. Rows above the dotted line refer to unvegetated samples.

\begin{tabular}{ccccc}
\hline Sample & \% Mixture 1 & \% Mixture 2 & Sum (\%) & Max. error (\%) \\
\hline S & 8 & 94 & 102 & 6 \\
SAP & 57 & 52 & 109 & 7 \\
STS & 65 & 38 & 103 & 5 \\
SAT & 91 & 8 & 99 & 3 \\
SAPAT & 95 & 4 & 99 & 2 \\
STSAT & 107 & -1 & 106 & 10 \\
SFR & 88 & -3 & 85 & 9 \\
SAPFR & 85 & 13 & 97 & 1 \\
STSFR & 95 & 0 & 95 & 7 \\
\hline
\end{tabular}




\section{Figure Captions}

Fig. 1. Set of Zn K-edge $\mu$-EXAFS spectra recorded on points-of-interest of contrasted chemical composition on sample thin sections. Spectra are classified into three groups according to their shape. One spectrum differed markedly from the others and is plotted separately in Figure 2.

Fig. 2. Zn K-edge $\mu$-EXAFS spectrum measured on sample SFR (plain line) and onecomponent fit with gahnite (dotted line).

Fig. 3. (a,b) Backscattered electron SEM image, and (c) EDS spectrum of a Zn-rich spot from sample STSFR. (d) The Zn K-edge $\mu$-EXAFS spectrum recorded at this spot (I \# 3, solid line) was simulated with $76 \%$ of $\mathrm{ZnS}$ (dotted line). The difference from $100 \%$ is due to the overabsorption effect.

Fig. 4. (a) Zn K-edge $\mu$-EXAFS spectrum (II \# 2) of a Zn-rich spot from sample SFR (solid line) compared to trioctahedral phyllosilicate references (kerolite) with varying $\mathrm{Zn} / \mathrm{Mg}$ ratio: $3.0: 0.0$ (ZnKer300), $2.1: 0.9($ ZnKer210) and $0.03: 2.97$ (ZnKer003) (dotted line), and (b) Fourier transform of spectrum II \# 2 (solid line) together with ZnKer210 (dotted line).

Fig. 5. Successful and selected unsuccessful target transformations of $\mathrm{Zn}$ reference compounds: Zn-reacted hydroxylapatite (ZnPhos), sphalerite (ZnS), high-Zn kerolite $\left(\mathrm{Si}_{4}\left(\mathrm{Mg}_{0.9} \mathrm{Zn}_{2.1}\right) \mathrm{O}_{10} \cdot \mathrm{nH}_{2} \mathrm{O}, \mathrm{ZnKer} 210\right),(\mathrm{Zn}, \mathrm{Al})$-hydrotalcite $\left(\mathrm{Zn}_{2} \mathrm{Al}(\mathrm{OH})_{6} \cdot\left(\mathrm{CO}_{3}\right)_{0.5}, \mathrm{ZnHyd}\right)$, gahnite $\left(\mathrm{ZnAl}_{2} \mathrm{O}_{4}\right), \mathrm{Zn}$-sorbed ferrihydrite $(\mathrm{ZnFh})$, hopeite $\left(\mathrm{Zn}_{3}\left(\mathrm{PO}_{4}\right)_{2} \cdot 4 \mathrm{H}_{2} \mathrm{O}\right), \mathrm{Zn}$-containing goethite $(\alpha[\mathrm{Fe}, \mathrm{Zn}] \mathrm{OOH}, \mathrm{ZnGoet})$, franklinite $\left(\mathrm{ZnFe}_{2} \mathrm{O}_{4}\right)$, low-Zn kerolite 
$\left(\mathrm{Si}_{4}\left(\mathrm{Mg}_{2.7} \mathrm{Zn}_{0.03}\right) \mathrm{O}_{10} \cdot \mathrm{nH}_{2} \mathrm{O}, \mathrm{ZnKer003}\right)$, and zincite $(\mathrm{ZnO})$. Solid line: experimental spectrum; dotted line : target transformed spectrum.

Fig. 6. (a) Zn K-edge $\mu$-EXAFS spectra (solid line) for spots I \# 1 (from sample STSFR), (b) for spot II \# 5 (from sample SAP), and (c) from spot III \# 1 (from sample STSAT), and their simulations using one, two and three components (dotted line).

Fig. 7. (a) Backscattered electron SEM image, and (b) EDS spectrum of spot II \# 4 (from SAP sample), and (c) its Zn K-edge $\mu$-EXAFS spectrum (solid line) modelled by one- and twocomponents (dotted line).

Fig. 8. (a) Zn K-edge $\mu$-EXAFS spectrum (solid line) for spot II \# 7 (from sample SAP) together with one- and two-component fits using either ZnHyd or ZnKer210 (dotted line), and (b) their respective radial structure functions (RSFs). The spectrum is best reproduced using ZnHyd (hydrotalcite).

Fig. 9. Polyhedral representation of the structure of high-Zn kerolite and the octahedral sheet of (Zn-Al)-hydrotalcite $\left(\mathrm{Zn}_{2} \mathrm{Al}(\mathrm{OH})_{6} \cdot\left(\mathrm{CO}_{3}\right)_{0.5}\right)$.

Fig. 10. (a) Comparison of Zn K-edge spectra, and (b) radial structure functions (RSFs) for high-Zn kerolite and (Zn,Al)-hydrotalcite. The EXAFS spectrum of the phyllosilicate has a diagnostic oscillation at $5.2 \AA^{-1}$, and its RSF displays a third peak at $\sim 3.9 \AA$ which is absent in (Zn,Al)-hydrotalcite. 
Fig. 11. Zn K-edge powder EXAFS spectra of samples described in Table 3. Arrows point to spectral modifications caused by mineral amendments and plants in comparison to the control sediment (S). These modifications are more pronounced in vegetated pots.

Fig. 12. Radial structure functions (RSFs) of the EXAFS spectra for the various types of substrates compared to RSFs for sphalerite (ZnS) and Zn-phosphate (ZnPhos). Only one RSF of the vegetated substrates is shown (STSAT) because they are all similar. The first peak position and imaginary part for the control sediment (S) are like $\mathrm{ZnS}$ (evidence for $\mathrm{Zn}-\mathrm{S}$ atomic pairs), whereas they are like $\mathrm{ZnPhos}$ in the presence of plants (evidence for $\mathrm{Zn}-\mathrm{O}$ atomic pairs). The SAP and STS RSFs have an intermediate shape.

Fig. 13. Zn K-edge powder-EXAFS spectrum of the bulk sediment (S, solid line) with one-, two- and three-component fits using ZnS, ZnFh, ZnHyd, and ZnKer210 (dotted line). The use of either ZnHyd or ZnKer210 as third component yielded a similar fit quality.

Fig. 14. Zn K-edge spectra of the various bulk samples (solid lines) with their best simulations (dotted lines). The accuracy on the proportion of species is estimated to $10 \%$ of the total amount of zinc.

Fig. 15. Fractional amounts of $\mathrm{Zn}$ species in the bulk samples. Percentages reported in the row "with plants" are averaged over all the various vegetated samples.

Fig. 16. Experimental aqueous $\mathrm{Zn}(\diamond), \mathrm{Ca}(\triangle)$ and $\mathrm{P}(\boldsymbol{\nabla})$ concentrations compared to saturation concentrations of $\mathrm{Zn}$ for, (a), Zn hydroxide, hydrotalcite and $\mathrm{Zn}$ carbonate at equilibrium $\mathrm{pCO}_{2}$ concentration of $10^{-2.5}$ atm., (b) hopeite and scholzite at different $[\mathrm{PO} 4]_{\mathrm{aq}}$ concentrations (low and high), and (c) Zn-kerolite (solid lines). In b), low and high phosphate 
concentrations were estimated from experimental data. In c), the $\mathrm{Zn}$ saturation concentration of Zn-kerolite (solid lines) was calculated for $0.1\left(\mathrm{Si}_{\text {low }}\right)$ and $1.0\left(\mathrm{Si}_{\text {high }}\right) \mathrm{mmol} \mathrm{L}^{-1} \mathrm{Si}(\mathrm{OH})_{4}$ concentrations and two solubility constants for Zn-kerolite. The saturation concentration of $\mathrm{Al}$ in equilibrium with gibbsite is given in all figures for calibration purposes between the three plots. 

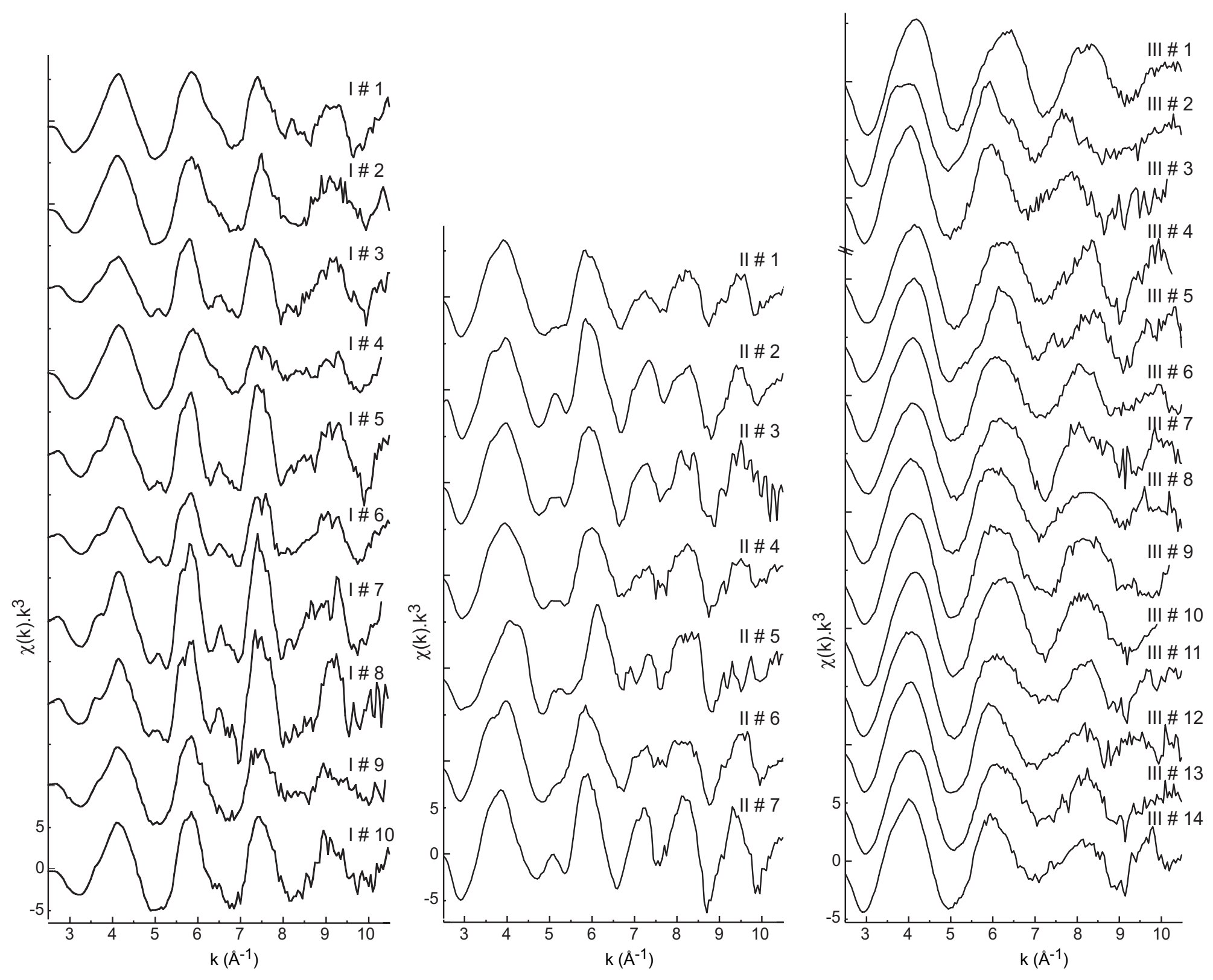

Fig. 1 


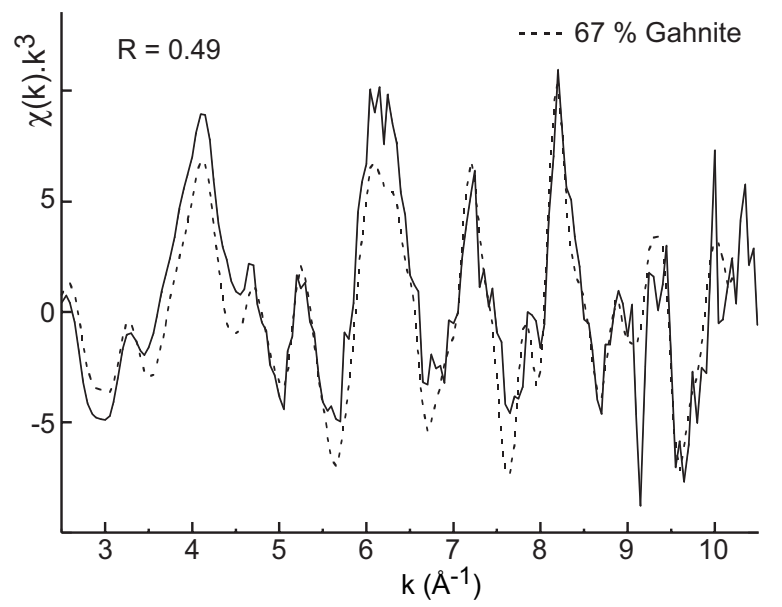

Fig. 2 


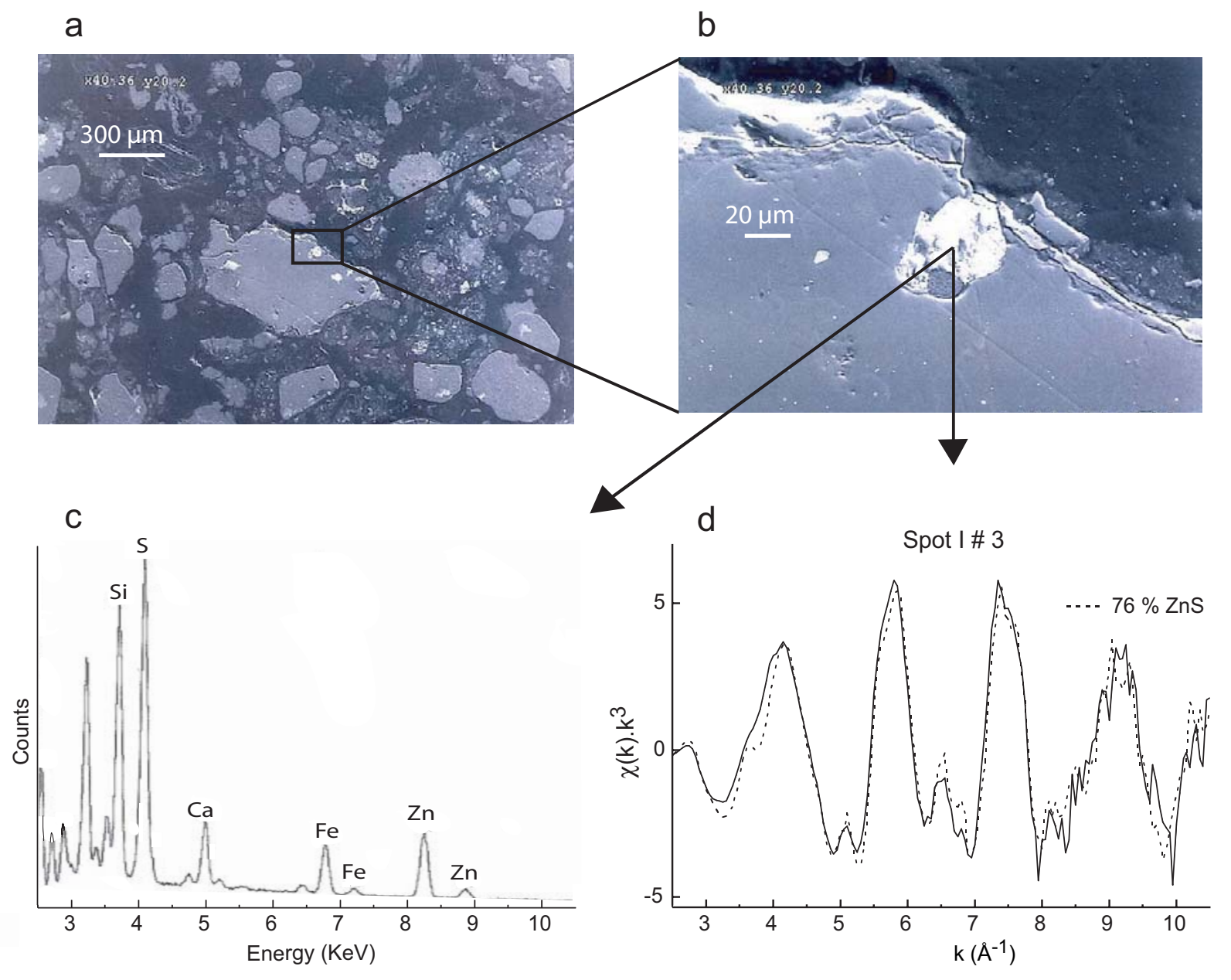

Fig. 3 

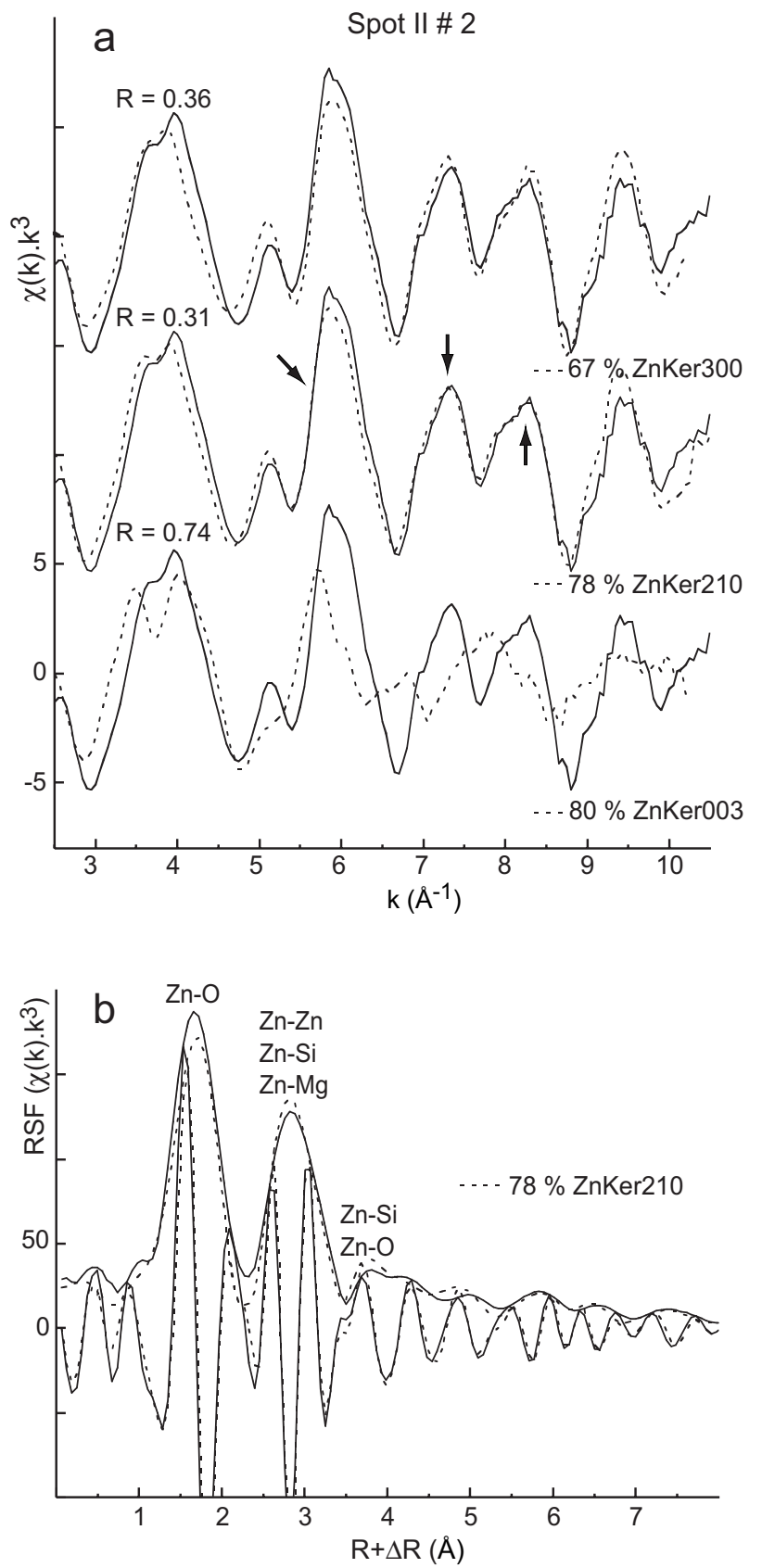

Fig. 4 

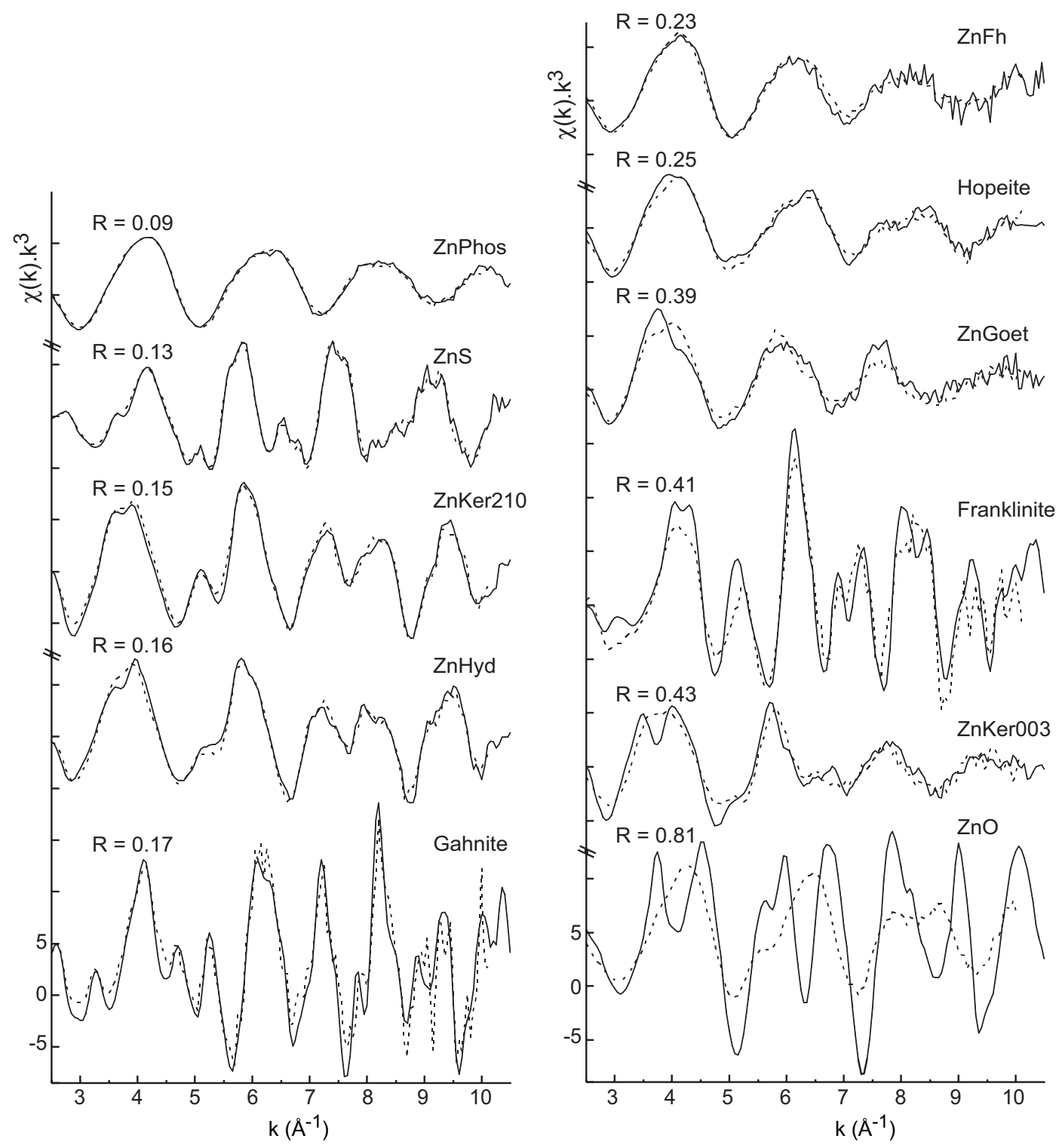

Fig. 5 

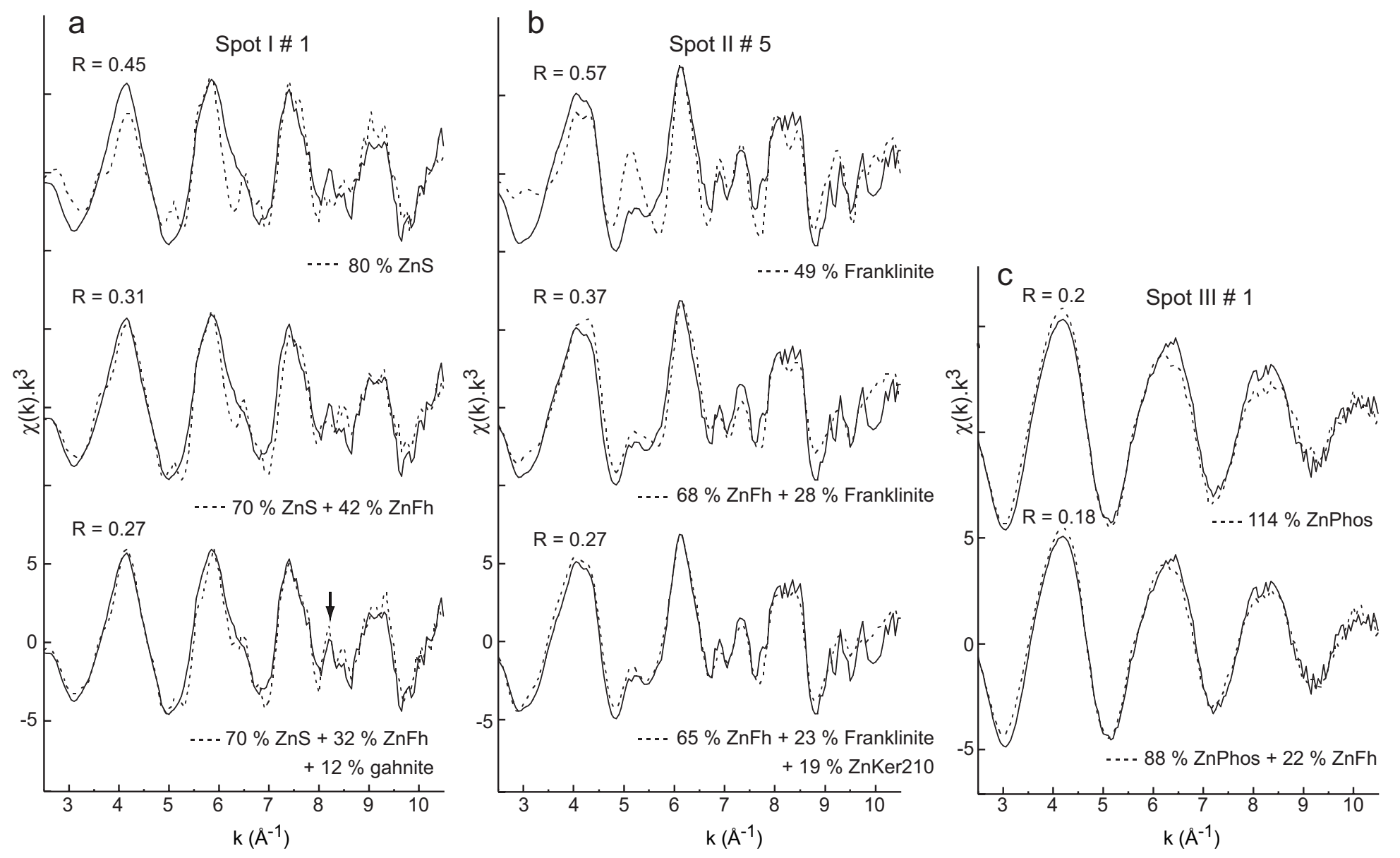


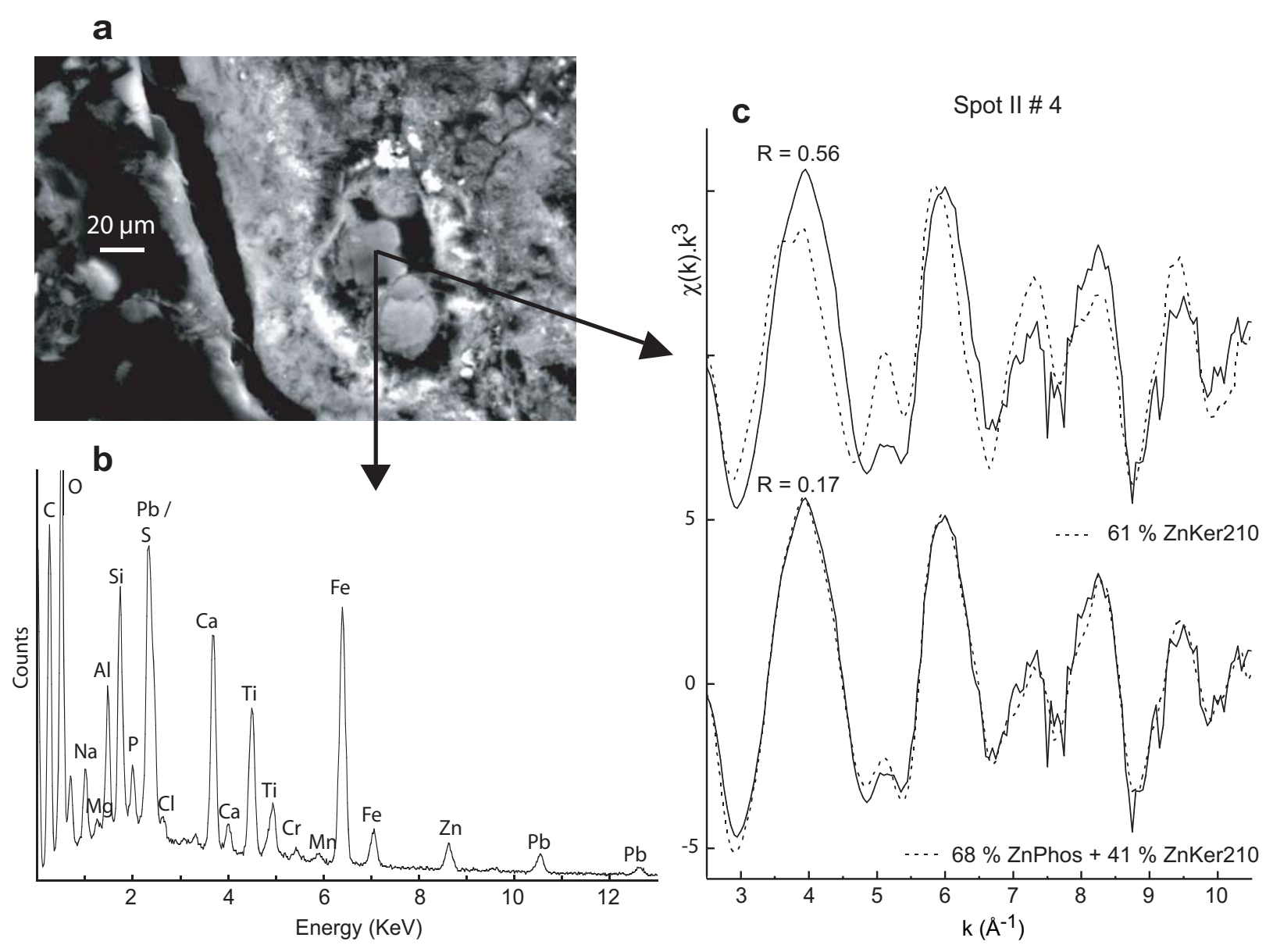

Fig. 7 
a
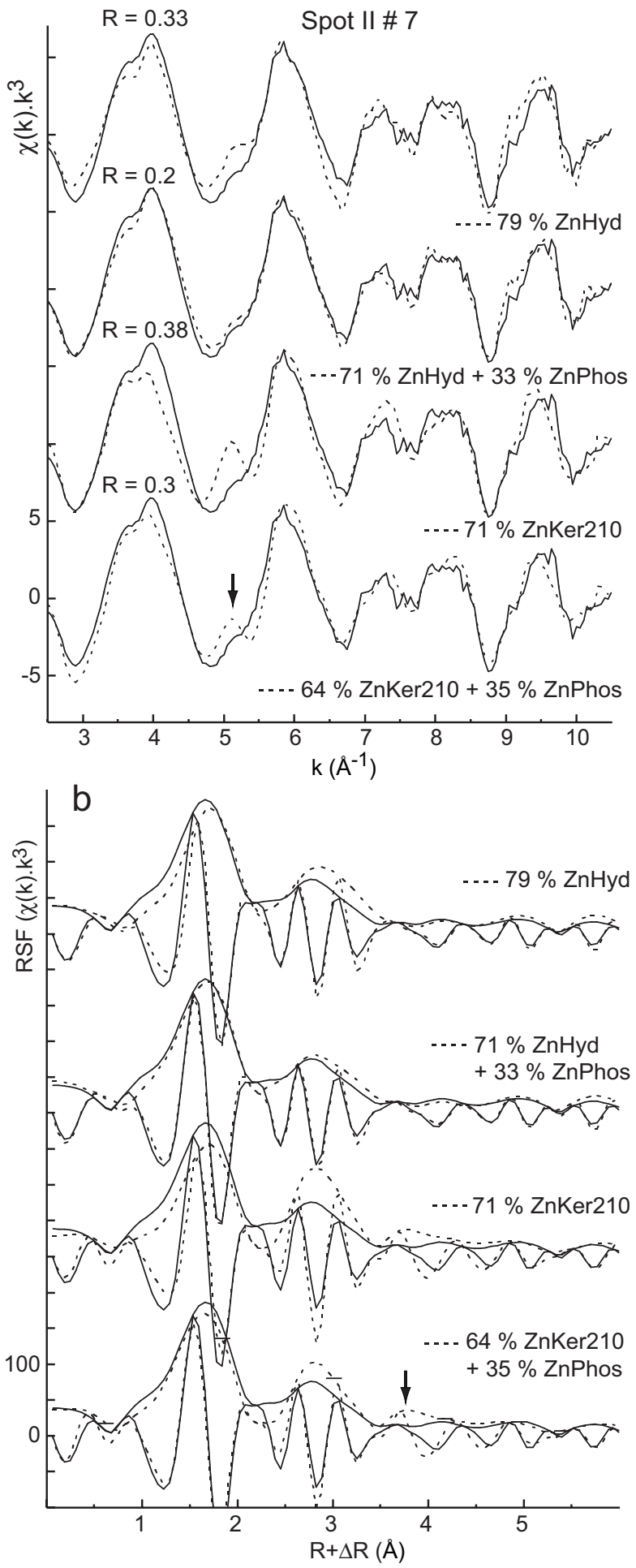

Fig. 8 
High-Zn kerolite

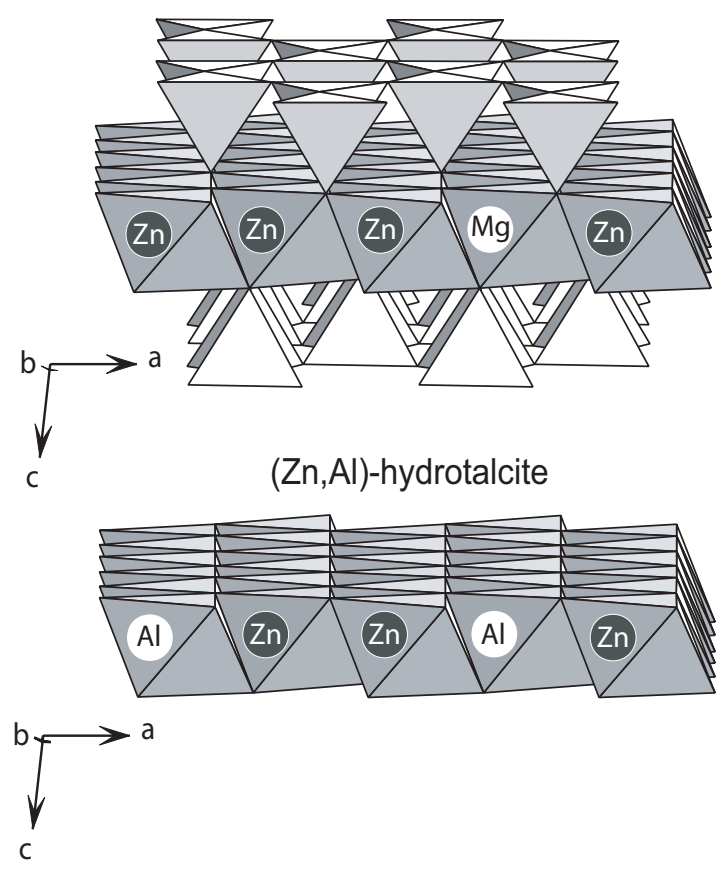

Fig. 9 

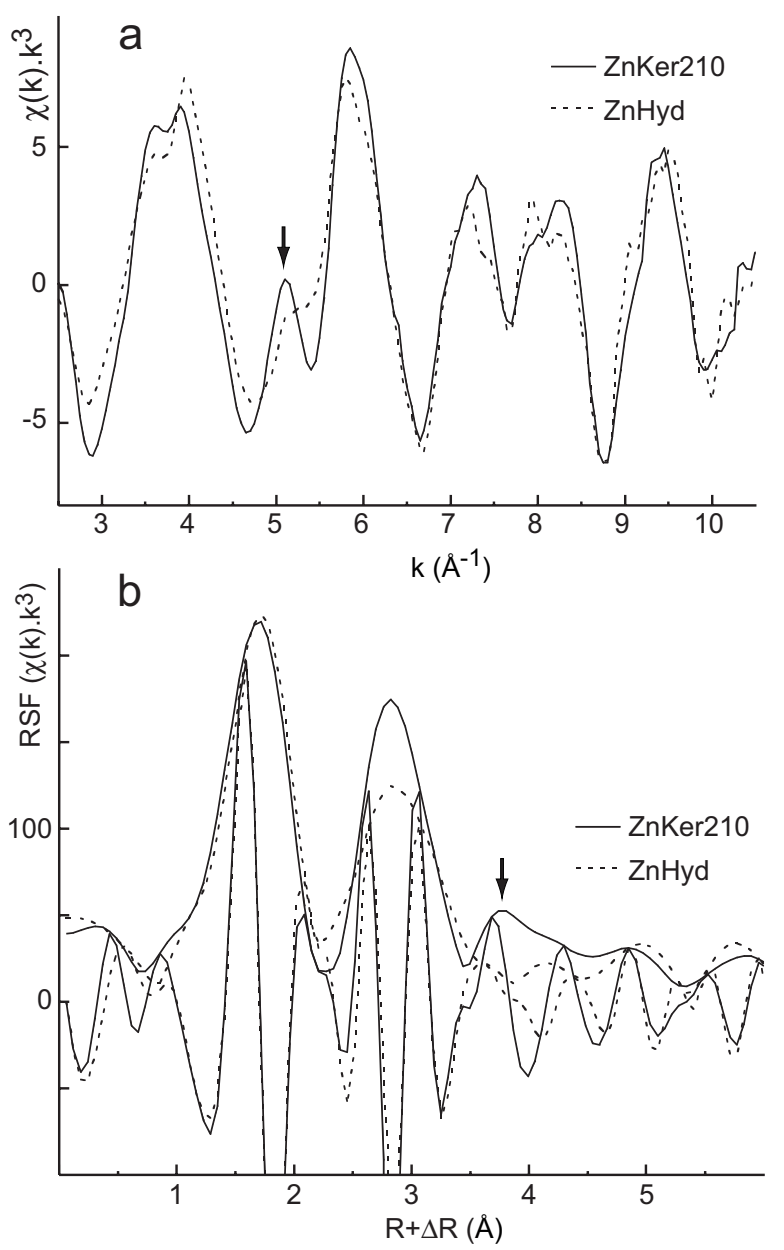

Fig. 10 


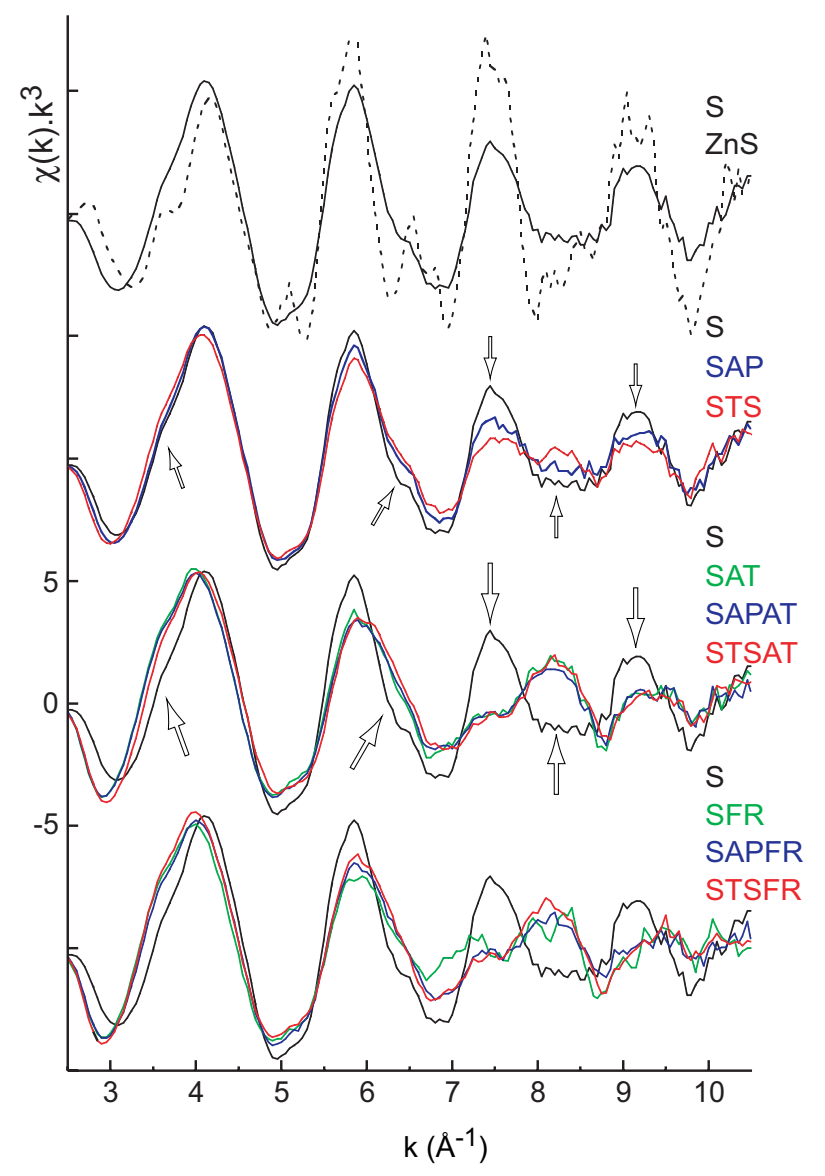

Fig. 11 


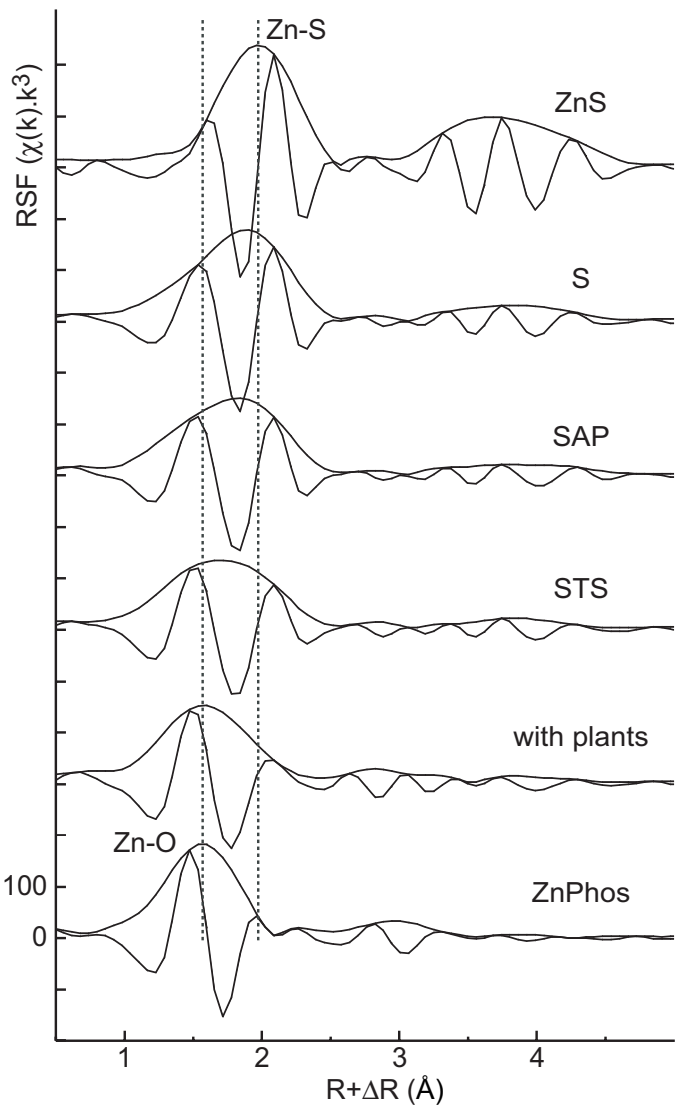

Fig. 12 


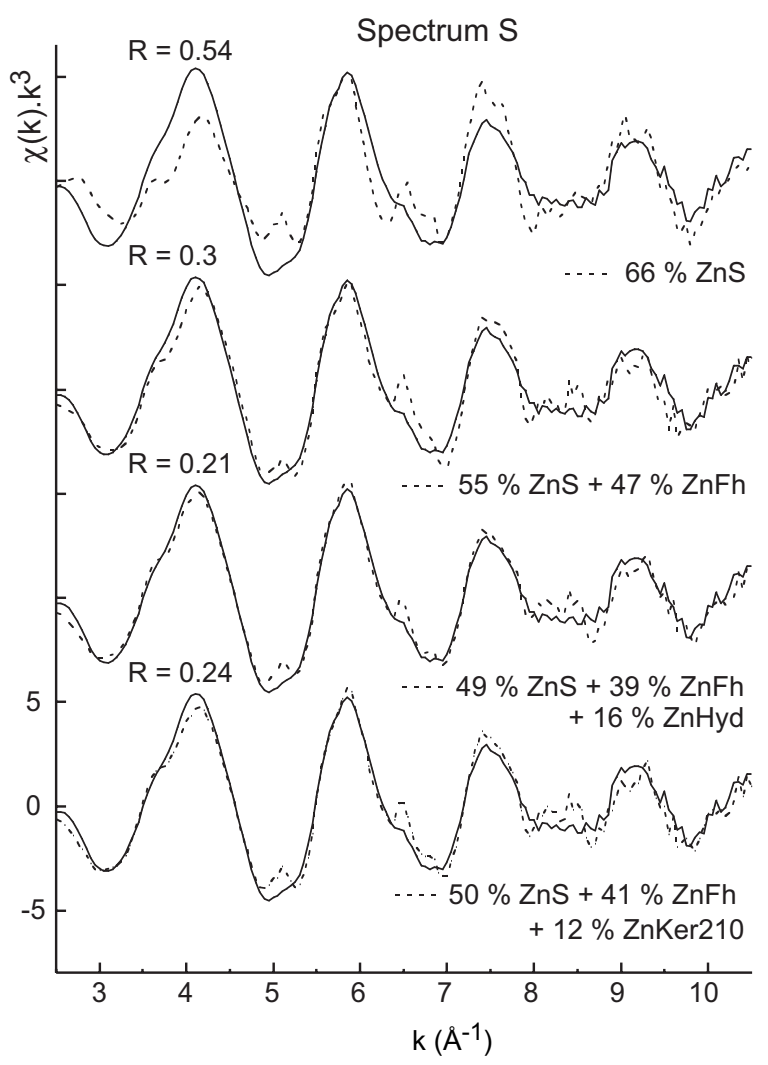

Fig. 13 


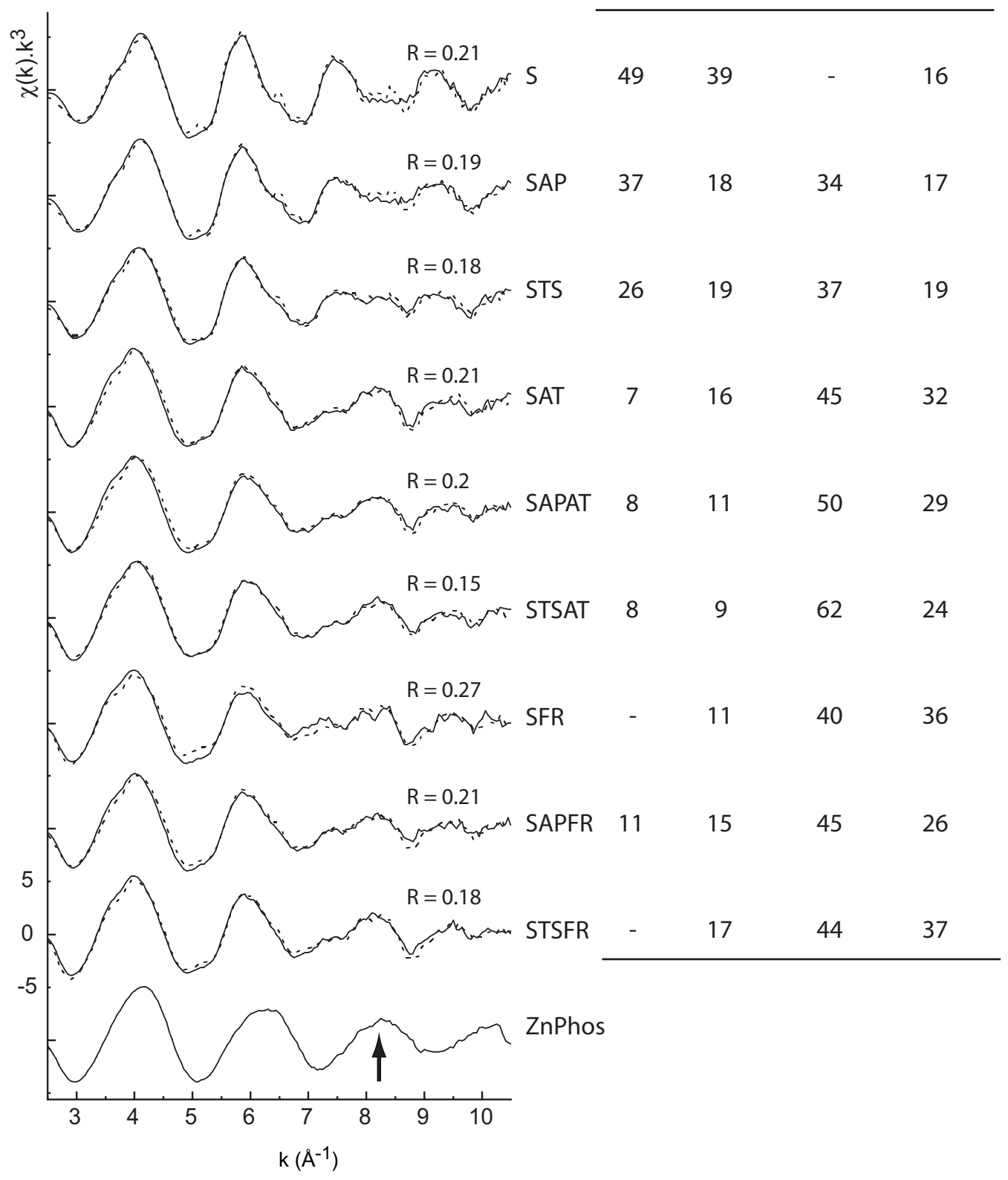

Fig. 14 


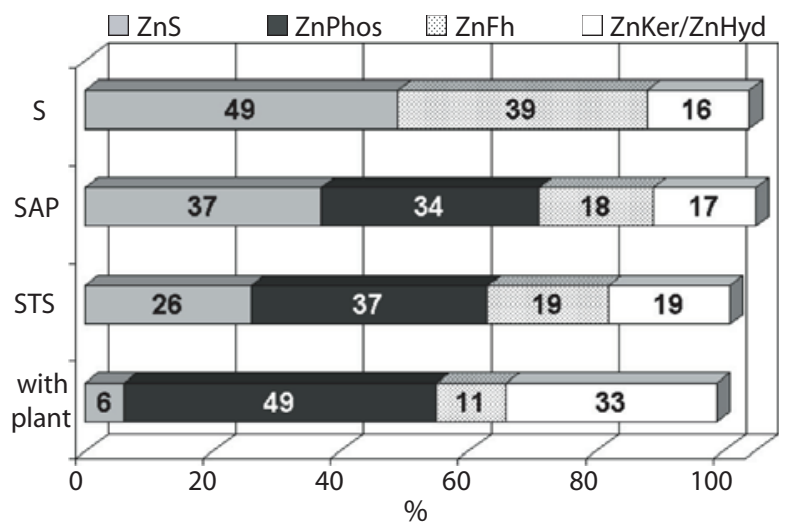

Fig. 15 

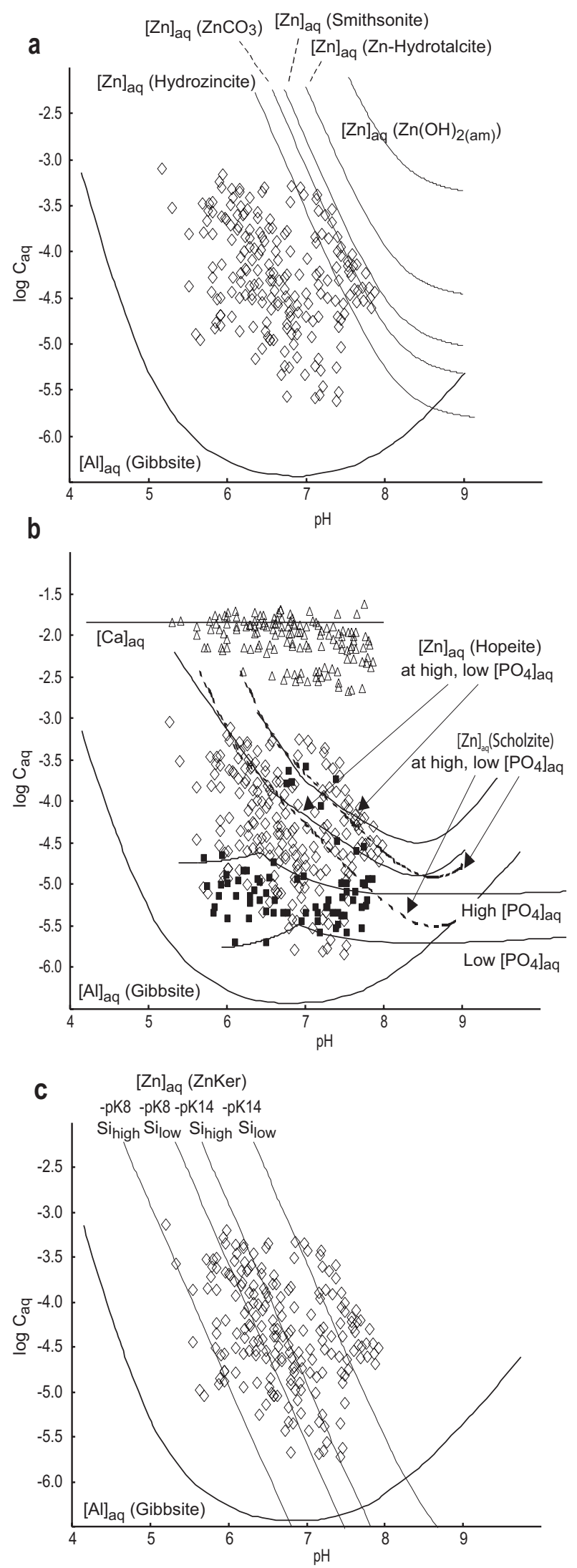

Fig. 16 